\title{
Development of a plug-and-play fire protection system for steel columns
}

\author{
Jérôme Randaxhe ${ }^{1,2}$, Nicoleta Popa ${ }^{1}$, Olivier Vassart ${ }^{1}$, Nicola Tondini ${ }^{2}$ \\ ${ }^{1}$ Global R\&D Center of ArcelorMittal, Esch-sur-Alzette, Luxembourg \\ jerome.randaxhe@arcelormittal.com; nicoleta.popa@arcelormittal.com; olivier.vassart@arcelormittal.com
}

2Department of Civil, Environmental and Mechanical Engineering, University of Trento, Italy nicola.tondini@unitn.it

\begin{abstract}
The paper presents the development of an innovative cost-effective fire protection system for steel columns, which is quick and easy to install and to dismantle. This protection is designed to be a plug-and -play system made of two half-protections with a U-shape to encapsulate a column and to connect each other. They are composed of high-density rock wool boards arranged in U-shape steel sheets presenting a system of claws to ensure their connection. Small-scale experimental tests were performed to evaluate the insulating efficiency of the system and the thermal behaviour of the connection claws. Numerical models were developed with the finite elements software ABAQUS and SAFIR and were then calibrated based on experimental results. Subsequently, full-scale experimental tests were performed according to the European norm EN13381-4 and the results assessment certified that the fire protection is effective for steel profiles with a section factor going from 42 to $103 \mathrm{~m}^{-1}$ and maintain their temperature below 550 ${ }^{\circ} \mathrm{C}$ when exposed to a standard fire for $120 \mathrm{~min}$. Finally, a cost analysis was performed to attest the competitivity of the plug-and-play fire protection system by considering direct and indirect costs.
\end{abstract}

Keywords: steel structure, fire protection, standard fire, FE thermal analysis, rock wool board, steel sheets 


\begin{tabular}{|c|c|c|}
\hline \multicolumn{3}{|c|}{ Nomenclature } \\
\hline$A_{p} / V$ & nominal box section factor of steel profile & {$\left[\mathrm{m}^{-1}\right]$} \\
\hline$\lambda_{\mathrm{RW}}$ & theoretical thermal conductivity of rock wool & {$[\mathrm{W} / \mathrm{mK}]$} \\
\hline $\mathrm{C}_{\mathrm{RW}}$ & specific heat of rock wool & {$[\mathrm{J} / \mathrm{kgK}]$} \\
\hline$\rho_{\mathrm{RW}}$ & density of rock wool & {$\left[\mathrm{kg} / \mathrm{m}^{3}\right]$} \\
\hline $\mathrm{W}_{\mathrm{RW}}$ & water content of rock wool & {$\left[\mathrm{kg} / \mathrm{m}^{3}\right]$} \\
\hline$\alpha_{c, \text { hot }}$ & convection coefficient for hot surface & {$\left[\mathrm{W} / \mathrm{m}^{2} \mathrm{~K}\right]$} \\
\hline$\alpha_{c, \text { cold }}$ & convection coefficient for cold surface & {$\left[\mathrm{W} / \mathrm{m}^{2} \mathrm{~K}\right]$} \\
\hline$\varepsilon_{\mathrm{RW}}$ & relative emissivity of rock wool & {$[-]$} \\
\hline $\mathrm{E}_{\mathrm{c}}$ & Young modulus in compression of rock wool & {$[\mathrm{MPa}]$} \\
\hline $\mathrm{C}_{\text {Num. } \mathrm{i}}$ & calibration coefficient & {$[-]$} \\
\hline$\lambda_{\text {Num.i }}$ & calibrated thermal conductivity of rock wool & {$[\mathrm{W} / \mathrm{mK}]$} \\
\hline$\lambda_{\text {avg }}$ & average of $\lambda_{\text {Num.i }}$ & {$[\mathrm{W} / \mathrm{mK}]$} \\
\hline$\sigma$ & standard deviation of of $\lambda_{\text {Num.i }}$ & {$[\mathrm{W} / \mathrm{mK}]$} \\
\hline$\lambda_{\beta, 50 \%}$ & $50^{\text {th }}$ fractile of the beta distribution of $\lambda_{\text {Num.i }}$ & {$[\mathrm{W} / \mathrm{mK}]$} \\
\hline$d_{p}$ & thickness of the protection layer & {$[\mathrm{m}]$} \\
\hline$\lambda_{p}$ & thermal conductivity of the protection & {$[\mathrm{W} / \mathrm{mK}]$} \\
\hline$C_{p}$ & specific heat of the protection & {$[\mathrm{J} / \mathrm{kgK}]$} \\
\hline $\mathrm{C}_{\mathrm{a}}$ & specific heat of steel & {$[\mathrm{J} / \mathrm{kgK}]$} \\
\hline$\rho_{p}$ & protection density & {$\left[\mathrm{kg} / \mathrm{m}^{3}\right]$} \\
\hline$\rho_{a}$ & steel density & {$\left[\mathrm{kg} / \mathrm{m}^{3}\right]$} \\
\hline$\theta_{\mathrm{g}}(\mathrm{t})$ & gas temperature at time $t$ & {$\left[{ }^{\circ} \mathrm{C}\right]$} \\
\hline$\theta_{a}(t)$ & steel temperature at time $\mathrm{t}$ & {$\left[{ }^{\circ} \mathrm{C}\right]$} \\
\hline$\Delta \theta_{\mathrm{g}}(\mathrm{t})$ & gas temperature increase during $\Delta t$ & {$\left[{ }^{\circ} \mathrm{C}\right]$} \\
\hline$\Delta \theta_{\mathrm{a}}(\mathrm{t})$ & steel temperature increase during $\Delta \mathrm{t}$ & {$\left[{ }^{\circ} \mathrm{C}\right]$} \\
\hline$\Delta \mathrm{t}$ & time step & {$[\mathrm{s}]$} \\
\hline$\theta_{\mathrm{a}}$ & design temperature & {$\left[{ }^{\circ} \mathrm{C}\right]$} \\
\hline$\lambda_{\theta a}$ & predicted thermal conductivity of rock wool for $\theta a$ & {$[\mathrm{~W} / \mathrm{mK}]$} \\
\hline$a_{i}$ & regression coefficient & {$[-]$} \\
\hline$\Delta \mathrm{L}_{\text {Tot }}(\mathrm{t})$ & total axial displacement at time $\mathrm{t}$ & {$[\mathrm{mm}]$} \\
\hline$\Delta \mathrm{L}_{\text {Therm. }}(\mathrm{t})$ & thermal expansion at time $t$ & {$[\mathrm{~mm}]$} \\
\hline$\Delta \mathrm{L}_{\text {Mech. }}(\mathrm{t})$ & mechanical axial displacement at time $\mathrm{t}$ & {$[\mathrm{mm}]$} \\
\hline$T(t)$ & overall mean temperature of loaded profile at time $t$ & {$\left[{ }^{\circ} \mathrm{C}\right]$} \\
\hline $\mathrm{T}_{0}$ & overall mean temperature of loaded profile at time $t=0$ & {$\left[{ }^{\circ} \mathrm{C}\right]$} \\
\hline$\alpha$ & thermal expansion coefficient of steel & {$\left[{ }^{\circ} \mathrm{C}^{-1}\right]$} \\
\hline $\mathrm{L}$ & height of loaded profile & {$[\mathrm{m}]$} \\
\hline k & correction factor & {$[-]$} \\
\hline$t_{1}$ & time for loaded specimen to reach design temperature & [min] \\
\hline $\mathrm{t}_{1}$ & time for unloaded specimen to reach design temperature & [min] \\
\hline$t_{c}$ & corrected time for unloaded specimen to reach design temperature & [min] \\
\hline $\mathrm{S}$ & box section section factor for loaded steel profile & {$\left[\mathrm{m}^{-1}\right]$} \\
\hline $\mathrm{S}_{1}$ & box section section factor for unloaded steel profile & {$\left[\mathrm{m}^{-1}\right]$} \\
\hline D & protection thickness for loaded steel profile & [m] \\
\hline $\mathrm{D}_{1}$ & protection thickness for unloaded steel profile & [m] \\
\hline$b_{i}$ & regression coefficient & {$[-]$} \\
\hline$b_{i}^{\prime}$ & modified regression coefficient & {$[-]$} \\
\hline
\end{tabular}




\section{Introduction}

\subsection{Existing fire protection systems}

Passive fire protection systems for steel structures have been investigated for decades. Their role is to delay the heating of structural components by isolating them from fire. In this respect, Islam et al. [1] studied the vulnerability of steel columns under the standard ISO 834 heating curve [2] by using numerical analysis. Typically, existing fire protections are made of insulating materials which may be divided into three categories: intumescent paints, sprays and boards. Petukhovskaia [3] investigated and summarized passive fire protection methods of load-bearing structures in case of hydrocarbon fire. Leborgne and Thomas [4] depicted the three fire protection systems and described their application with their advantages and limits. The National Institute of Standards and Technology (NIST) [5] reported an overview of existing fire protections for structural steel with their advantages and disadvantages. Currently, almost all protections require important installation times on construction site, which represents costs and exposure to risks for technicians. A brief description of these fire protections is presented herein with their main properties.

Intumescent paint guarantees insulation efficiency for steel members by producing chemical reaction in event of fire. When heated to around $200{ }^{\circ} \mathrm{C}$, an intumescent paint layer expands to form a layer up to 50 times thicker, which ensures the insulation of the member. The layer thickness to be applied depends on the targeted fire resistance. As depicted in Figure 1a, paints offer a clean visual aspect. They can be applied by an off-site or in-site treatment depending on the project. In both cases, their proper application requires time and qualified labour which make these paints an expensive protection. Intumescent paints are suitable to protect complex structural connections and can be reused in case of building dismantlement. Lots of research is going on about intumescent coatings and its use in a performancebased fire engineering context when natural fire curves are used to investigate the structural fire behaviour. Lucherini and Maluk [6] reviewed intumescent coatings used for the fire-safe design of steel structures. De Silva et al. [7] experimentally investigated steel elements protected with intumescent coatings. Griffin [8] modelled the heat transfer across intumescent polymer paints. Gardelle et al. [9] studied a silicon-based coating. Luangtriratana et al. [10] quantified the thermal barrier efficiency of intumescent coatings. Chen et al. [11] studied the performance of ultrathin intumescent paint for steel plate at elevated temperature. Mariappan [12] reviewed the recently developed intumescent coatings for structural steel. These numerous studies were encouraged by the increase of the market demand for intumescent paints in the past decade.

Sprays can have different chemical compositions; as for example, they can be cementitious, gypsum, and vermiculite based. These products must be directly sprayed on structural members on site. The thickness to be sprayed also depends on the targeted fire resistance. Although the spray application is rapid, it is wet and requires a drying period which can delay the construction site progress. Indeed, an area where a structure is being sprayed cannot be occupied by other workers. As depicted in Figure $1 \mathrm{~b}$, the sprays visual aspect suits only very low frequented areas, for instance basements and car parks. Sprays offer the advantages to cover complex structural geometries and to be a low-cost solution, but they cannot be easily reused in case of building dismantlement. Fulmer [13] developed and patented a cementitious spray without using any adhesive. Zhang and Li [14] recently developed a spray adopting engineered cementitious composite technology to address durability issues. 
Boards can be made of gypsum, wood, or any other rigid insulating material such as rock wool. Protecting structural members with board requires a tailor-made installation on site. Boards need to be cut, attached to members with screws or glue and eventually finished to offer a good visual aspect if required. This is a time-consuming process. Even though boards can be made of cheap materials, they are usually an expensive solution due to the labour cost. As depicted in Figure 1c, when made of gypsum, boards solutions present a clean visual aspect which can suits any sort of building occupancy. However, that is not the case for all boards, as for example the ones made of rock wool. Globally, board systems used as fire protections for steel columns also benefit from research conduct in the development of fire resistance wall panels usually made of rock wool, mineral wool or gypsum. Zhang et al. [15] studied the fire resistance of tubular steel columns protected with gypsum boards, rock wool boards and blanket made of aluminasilica materials. Keerthan and Mahendran [16] numerically studied gypsum plasterboard panels under standard fire. Gottfried [17] developed and patented a board system to wrap structural steel members and made of several layers of insulating material. Zago and Keiser [18] developed and patented a rigid protection system composed of different components, made of gypsum boards surrounded by a steel sheet, to be screwed together. Different metallic connectors were developed to equip steel profiles flanges extremities and provide attaching surface to screw fire resistant gypsum boards. Parker [19] developed and patented a first version of such connectors and Ramos [20] developed and patented an alternative and continuous version of these connectors.

Considering existing fire protection systems, Akaa et al. [21][22] developed an analysis technique to select the optimal system based on structural performance and cost criteria. Lim et al. [23] used numerical analysis to evaluate the performance of passive fire protection in processing facilities. Existing fire protection systems differ in their global cost, installation process and visual aspect, although they all delay the heating of structural steel members. Obviously, fire protection visual aspect is correlated with costs and depends on the construction type and the architectural aesthetics that is being sought. Good visual aspects usually require higher costs. However, the key disadvantage shared by these systems remains the time required for their installation. The application of these fire protections must be all undertaken on construction sites, except for the intumescent paints when applied off-site. This observation raises two questions: cost and safety. The direct costs of a fire protection system are the ones related to materials and labour. The indirect costs are the ones generated within construction projects due to the installation time of the fire protection. These indirect costs can be significant in terms of delay, damage, or accessibility limitations for other workers. Regarding the safety, it is well known that construction sites are areas more exposed to risks and hazards than familiar environments such as manufacturing plants. It means that with a fire protection system that requires long installation delay, the exposure to risk for the installation technicians increases because workers must spend more time on site. Considering these two aspects, it seems relevant to develop an innovative fire protection system that addresses installation time issue, which intertwines costs and safety. Indeed, especially with current construction sites where the numbers of subcontractors and their interactions can be very important, it is in the community interest to design a safer and cost-efficient fire protection system. 


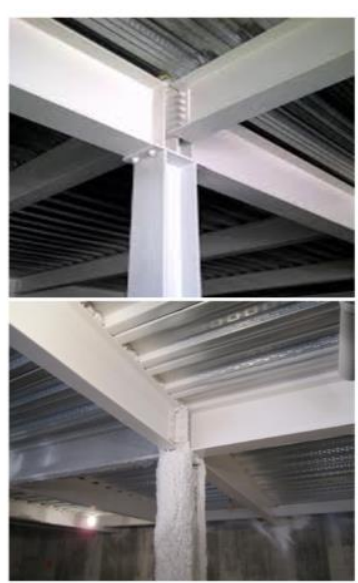

(a)

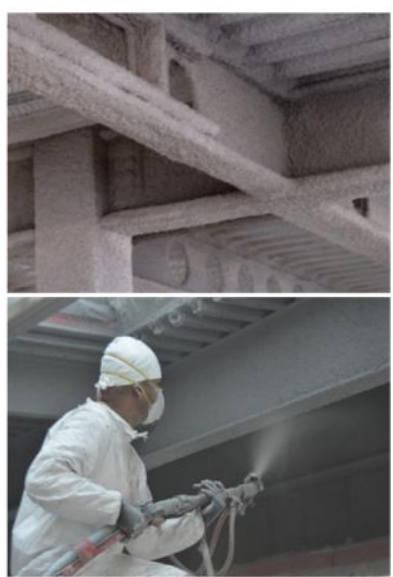

(b)

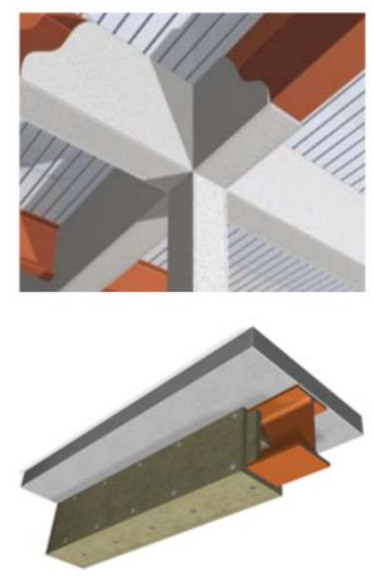

(c)

Figure 1 - Existing fire protection systems: a) Intumescent paints; b) Sprays; c) Boards

\subsection{Scope of the work}

The scope of this work is to develop an innovative fire protection system for steel columns exposed to the standard fire by maintaining their temperature below $550{ }^{\circ} \mathrm{C}$ for $120 \mathrm{~min}$. At $550^{\circ} \mathrm{C}$ steel retains $62.5 \%$ of its strength and it can be deemed as a limiting temperature in a simplified approach for which the loads in the fire situation can be taken as 0.65 of the loads at the Ultimate Limit States as for EN 1993-1-2 [24]. The system is designed to protect steel columns with $\mathrm{H}, \mathrm{I}$ and hollow square sections. It aims to simultaneously offer the advantages of the existing protection and to address their issues related to cost and safety. Therefore, the design of such a system started with the definition of the specifications to be fulfilled by the fire protection to be developed. Among these specifications listed in Table 1, the most innovative one is the plug-and-play connection system which facilitates short installation time and dismantlability. Indeed, the fire protection system must innovate in terms of installation ease and rapidity. The dismantlability aspect aims to meet the sustainability criteria that current projects has sometimes to fulfil when submitted for tender process. The work investigated all these aspects: fire performance and cost effectiveness. The paper is organised as follows: Section 2 describes the design of the fire protection system based on the specifications and on small-scale experimental tests. Section 3 reports the outcomes of small-scale experimental fire tests conducted on seven columns equipped with different fire protections. Section 4 presents the numerical models which were developed to analyse the behaviour of the protection when exposed to standard fire curve. Section 5 reports the implementation of large-scale experimental tests and the methodology prescribed by the norm EN13381-4 [25]. For that purpose, five specimens, presenting different section factors, were protected by the same fire protection system. Section 6 analyses the thermal data obtained from the large-scale experimental tests and assesses the thermal efficiency of the protection. This assessment follows a method defined by the norm leading to the certification of the fire protection. Design recommendations are also provided. Section 7 details a cost analysis for the fire protection developed and compares it with other protection systems based on direct and indirect costs. Finally, Section 8 draws conclusive remarks along with future perspectives. 
Table 1 - Fire protection specifications

\begin{tabular}{ll}
\hline & - "plug \& play" system \\
& - appropriate for steel columns exposed to fire on four sides \\
& - appropriate for $\mathrm{I}, \mathrm{H}$ and hollow square section types \\
& - R120 fire resistant \\
The fire protection & - effective for columns exposed to standard fire for $120 \mathrm{~min}$ by \\
main requirements & maintaining steel temperature below $550^{\circ} \mathrm{C}$ \\
& - composed by 2 elements \\
& - quick to install and dismantlable \\
& - light enough to be manipulated by two men \\
& - cost-effective \\
& - aesthetic \\
\hline
\end{tabular}

\section{Design of an innovative fire protection system for steel columns}

The two key-elements of the fire protection development were the selection of the components and the design of the connection system. In the case of sprays and paints, there is no proper fixing system since the insulating material is self-fixing on structural members. For systems made of boards, it is essential to use a reliable fixing system. Boards may be highly insulating, but if their fixations fail, their insulating effect is significantly decreased, as highlighted by Wang and Li [26] who studied fire resistance of steel columns when fire protection is partially damaged. First, to ensure the fire resistance of the protection itself for $120 \mathrm{~min}$, it was imperative to use non-flammable materials. Secondly, to facilitate a rapid installation on site, the insulating system had to be light and rigid enough to be manipulated with ease by two technicians. Especially for structural members presenting important heights, it was more convenient to deal with rigid components than smooth ones, such as blankets. To provide rigidity- and non-flammable aspects within the protection, it was decided to use high density rock wool boards and steel sheets. Nowadays, rock wool boards are already used as a fire protection system [27], but they require installation delay and aesthetic finishing. They are attached to steel structural members with glue or with specific pins directly welded on the member through the board. The use of steel sheets brings both rigidity and clean visual aspect to the protection. Additionally, steel sheets can ensure its own connection system. As depicted in Figure 2, the fire protection is made of two identical half-protections, prefabricated with steel sheets and rock wool boards. Steel sheets are formed with a $U$ shape inside which high density rock wool boards are positioned with glue. The extremities of the steel sheets are specifically bended like claws to generate the connection system of the protection. The connections are made of two complementary claws, male and female, clasping into each other to bond the two half-protections. When the protection is properly installed around a column, the rock wool boards are against the column, which ensures its insulation and maintains the connection claws clasped into each other. Furthermore, this connection system is designed to present a safe behaviour against thermal dilation effects. When a protected column is exposed to heat, the two-half protections can freely expand while the claws remain connected. This is shown in Section 4.1. with 3D thermo-mechanical analyses. The installation of the two half-protections and their connection requires the application of forces as depicted on Figure 3. When half-protections are installed around a column, rock wool boards are compressed against the flange of the profile and against 
each other while the claws push and slide along each other (Figure 3b). Once the relative displacement of the claws is adequate, the claws can clasp into each other (Figure 3c). It appeared that forces to be applied for the proper installation of the protection were very high. Therefore, clamps were used as tools to apply the appropriate pressure without impacting the protection integrity. However, the development of a more convenient tool could be the scope of future works.

Eventually, this plug-and-play system can be considered as a board system since its thermal efficiency is ensured with rock wool boards. The innovative aspect remains in the connection system generated by the steel sheets surrounding the boards. The use of steel sheets constitutes three advantages. It combines an easy assembling method, a pre-manufactured system and aesthetic aspects. Figure 4 illustrates two pictures of the fire protection applied around a $3 \mathrm{~m}$ high column. The main objectives and features resulting from the fire protection design are outlined below.

First the issue of thermal bridges at the connection level is carefully considered in the design. Therefore, the use of intumescent joint and the discontinuous set of rock wool boards inside steel sheets are contemplated options that are investigated in Section 3. Discontinuities within the global insulation thickness in the protection corners and at connection levels are illustrated in Figure 2.

Secondly, both claws, male and female claws ensuring the protection connection are designed to be continuous all along the height of the protection. However, considering important columns height, it requires a perfectly synchronised installation to permit the clasp all at once along the entire height. Since such installation appears complex to perform, it is decided to make the male claw discontinuous to allow a connection process like a zip connection, from the bottom to the top, as illustrated in Figure 5.

Thirdly, connection claws are designed with an angle of $45^{\circ}$ that allows ease of connection and mechanical resistance. For aesthetic concerns, claws are bent inside the protection which represents an obstacle for rock wool board. Thus, there are two options for the rock wool boards layout: i) rock wool boards are cut to perfectly fit the shape the claws; ii) rockwool board are cut with rectangular cross-section which reduces manufacturing costs but generates holes around connection claws. Both options and their thermal impact are investigated with in Section 3.

Finally, regarding the steel sheet thickness to be used and the length to be assigned to the connection claws, a good compromise between thermo-mechanical efficiency, protection weight and costs has to be found. Therefore, different thicknesses and lengths are evaluated experimentally in the next Section. 


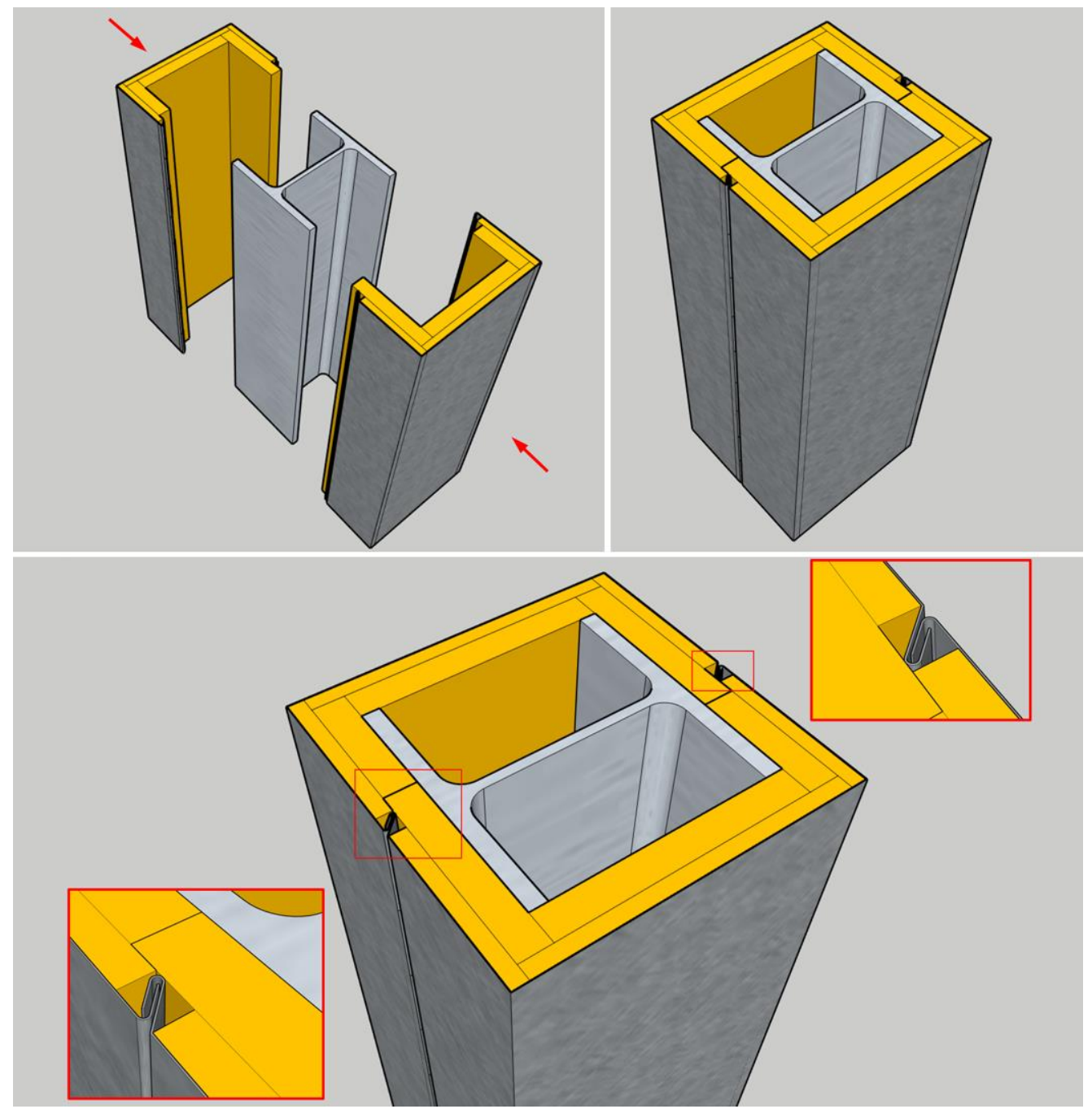

Figure 2 - Description of the fire protection: HEB240 protected with $45 \mathrm{~mm}$ of rock wool

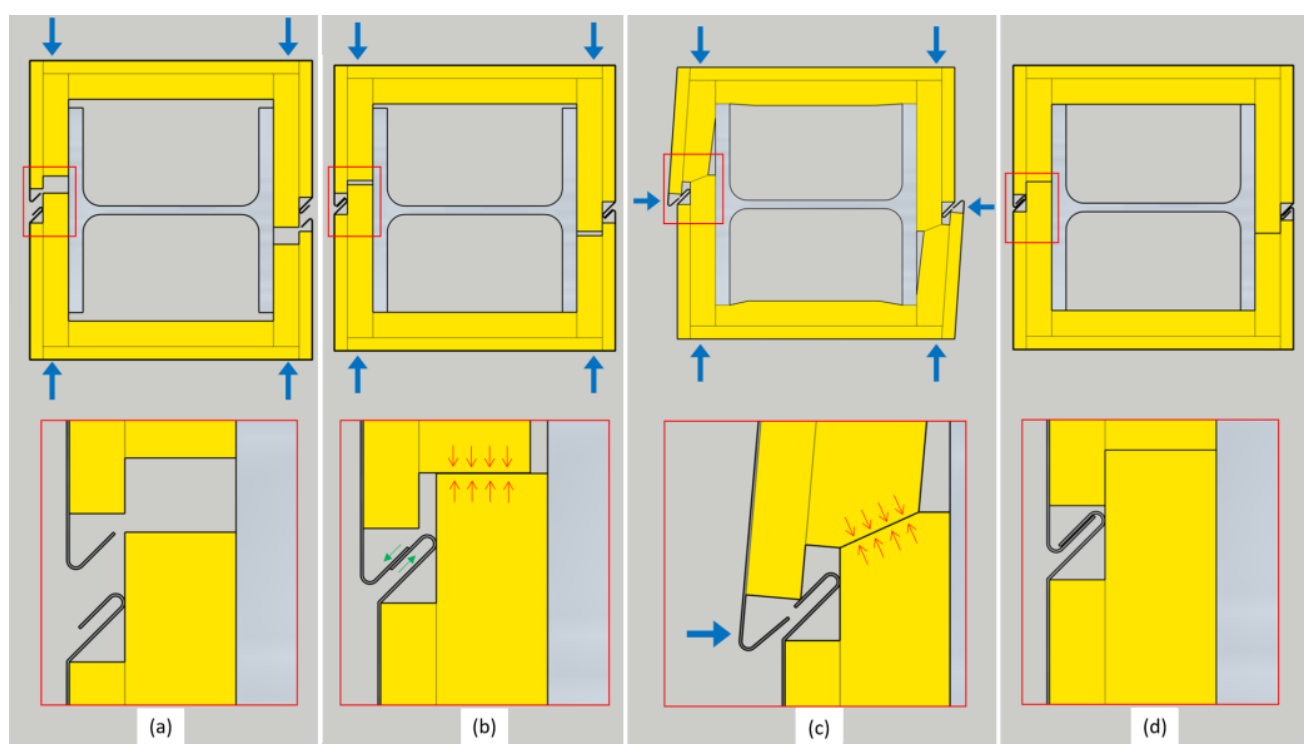

Figure 3 - Installation of the fire protection with a plug-and-play system 


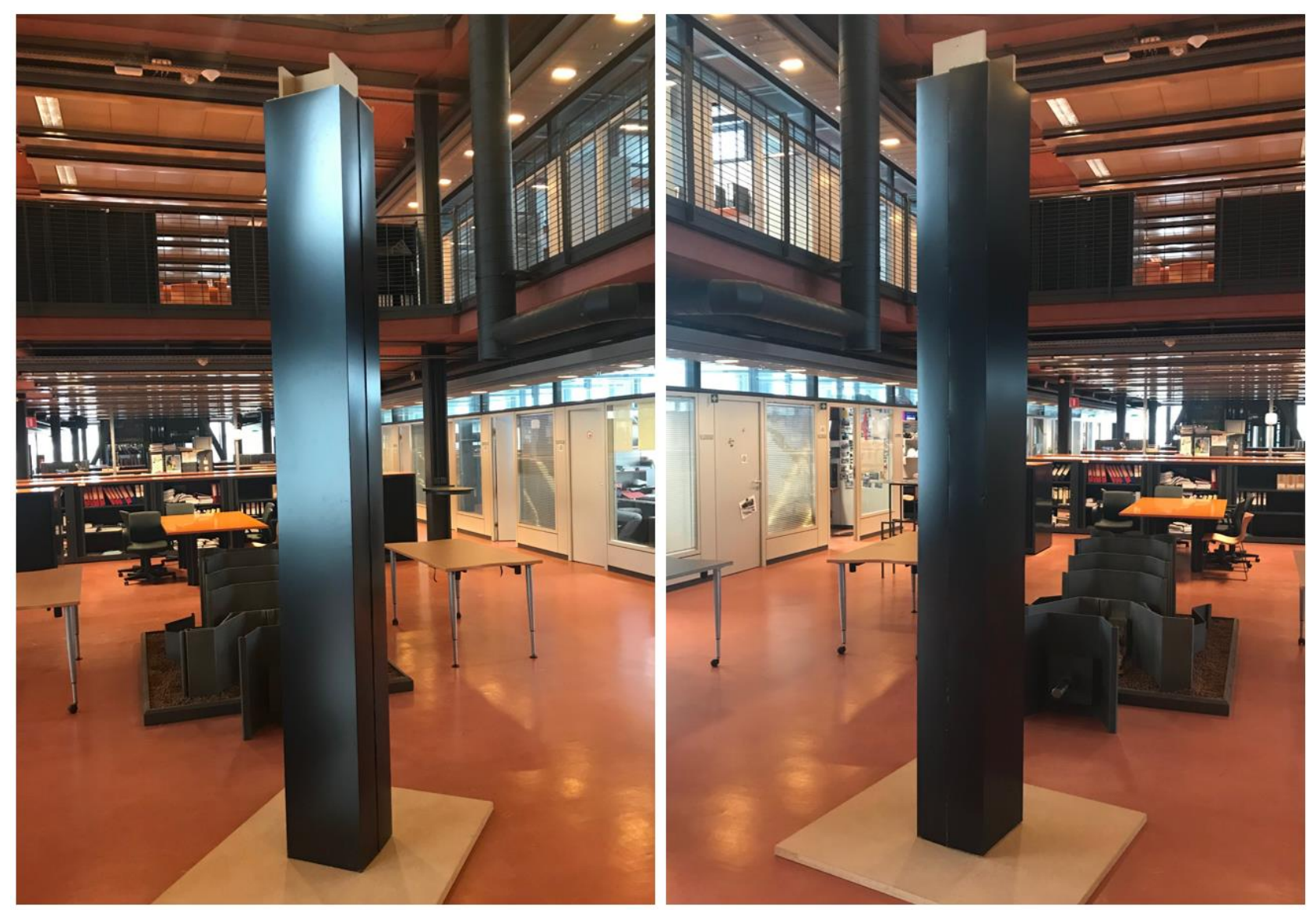

Figure 4 - The plug-and-play system protecting a $3 \mathrm{~m}$ high column

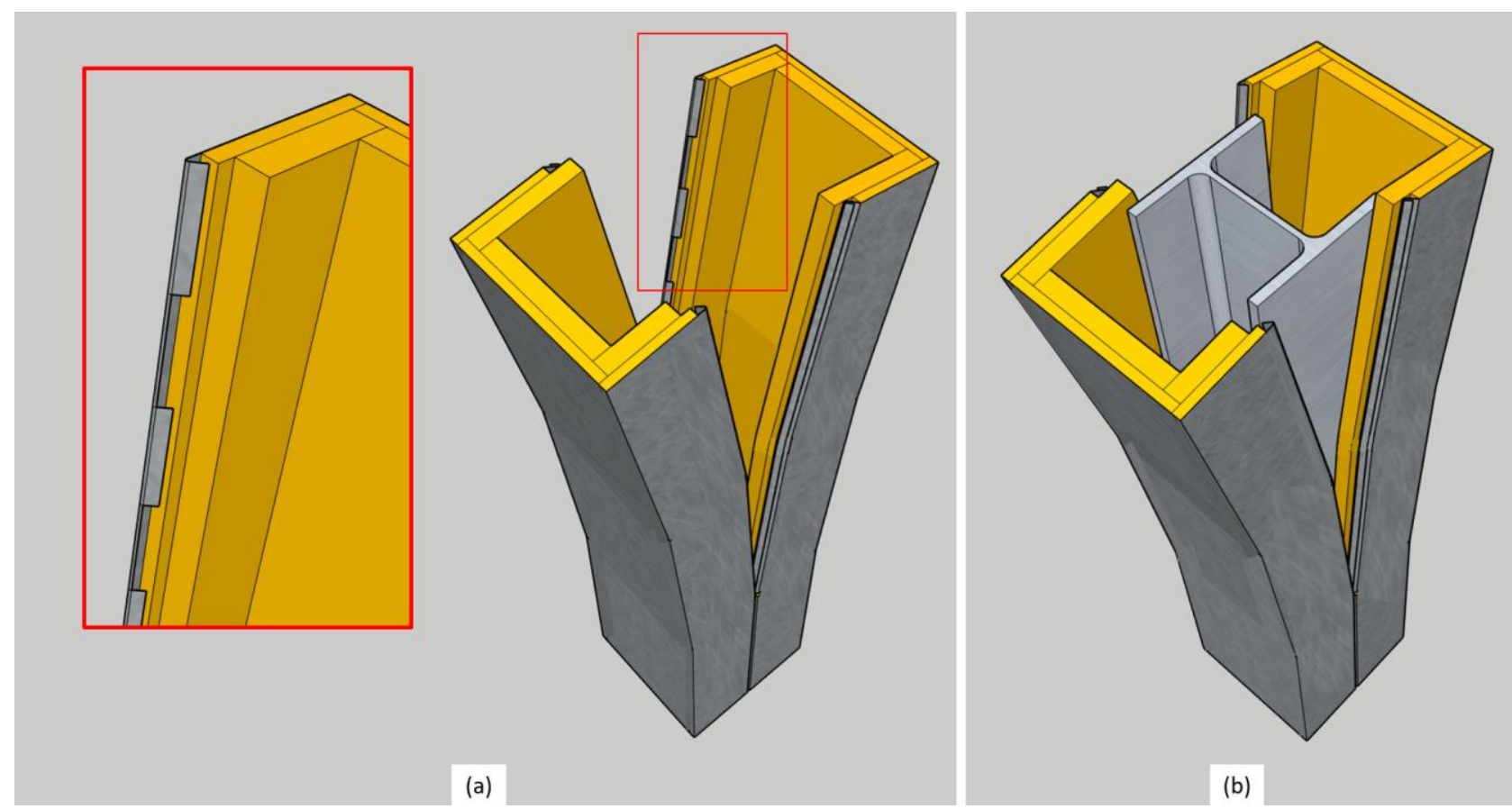

Figure 5 - Installation concept: a) Discontinuity of the male claws; b) Connection of two half protections around a steel profile 


\section{Small-scale experimental tests}

\subsection{Specimens and instrumentation}

Seven small-scale experimental fire tests were performed at the research centre of metallurgy (CRM) in Liège, Belgium. The ISO 834 standard heating curve was applied to the specimens [2]. Small-scale tests took place along with the design phase of the fire protection to simultaneously improve its development and to evaluate its thermal efficiency. The geometries of the seven specimens are depicted in Figure 6 where distinctive characteristics can be observed within the different specimens. As explained in Section 2 , these tests aimed to evaluate different design features and options. Thus, between Specimen 1 and Specimen 7, modifications were made to the fire protection. As illustrated in Figure 6, main modifications regard: intumescent joint; rock wool boards discontinuity at connection levels and within corners; discontinuity of male claws; holes at connection levels; steel sheet thickness and length of the connection claws. The properties of the seven specimens are summarised in the Table 2 . The scale of these experimental tests is considered as "small" due to the dimensions of the experimental furnace. Indeed, Figure 7a depicts the experimental furnace with a cubic volume of $0.512 \mathrm{~m}^{3}(0.8 \mathrm{~m} \times 0.8 \mathrm{~m} \times 0.8 \mathrm{~m})$ and a square opening at the ceiling level of $0.04 \mathrm{~m}^{2}(200 \mathrm{~mm} \times 200 \mathrm{~mm}$ ). Six specimens were inserted vertically in the furnace through this top opening and were therefore limited by its dimensions. They were HEB140 and HEB100 steel profiles respectively protected with $30 \mathrm{~mm}$ and $50 \mathrm{~mm}$ of rock wool, so that they sealed the opening by their own (Figure 7b). Specimen 7 was shorter and inserted laterally in the furnace by the front door, while the top opening was sealed with ceramic fibre (Figure 7c). It was a HEM220 steel profile protected with $45 \mathrm{~mm}$ of rock wool. In any case, the height of the specimens exposed to fire was limited to $0.8 \mathrm{~m}$. As described in Figure 8 , the seven specimens were instrumented in the same way, with 14 thermocouples. 7 thermocouples were set at $200 \mathrm{~mm}$ from the bottom while the 7 other ones were set at $60 \mathrm{~mm}$. They were welded on the profile, at mid-web, mid-flange and the extremities of the flanges. As indicated in Figure 8b, when specimens were inserted through the top opening, steel sheets were cut at the ceiling level of the furnace to reproduce realistic boundary conditions for the specimens.
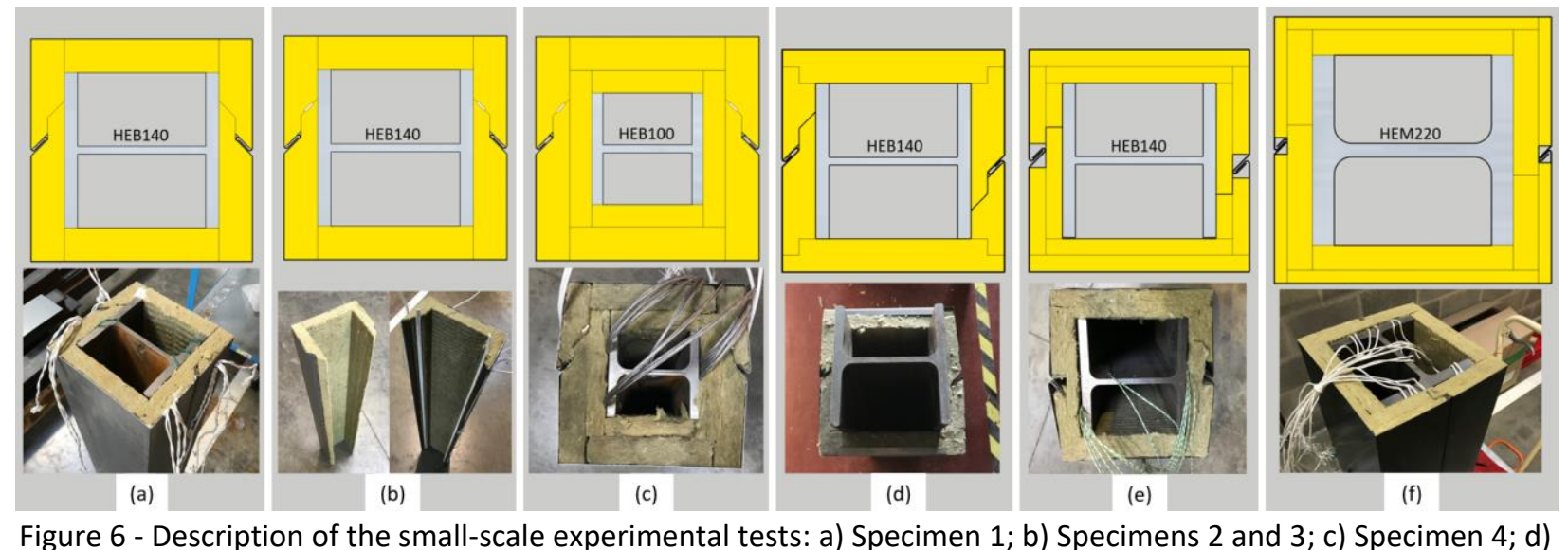

Figure 6 - Description of the small-scale experimental tests: a) Specimen 1; b) Specimens 2 and 3; c) Specimen 4; d) Specimen 5; e) Specimen 6; f) Specimen 7 
Table 2 - Properties of the small-scale experimental tests

\begin{tabular}{|c|c|c|c|c|c|c|c|c|c|}
\hline Specimen & Profile & $\begin{array}{c}\text { Box } \\
\text { section } \\
\text { factor } \\
\mathrm{A}_{\mathrm{p}} / \mathrm{V}\left[\mathrm{m}^{-1}\right]\end{array}$ & $\begin{array}{c}\text { Rock } \\
\text { wool } \\
\text { thickness } \\
{[\mathrm{mm}]}\end{array}$ & $\begin{array}{c}\text { Steel } \\
\text { sheet } \\
\text { thickness } \\
{[\mathrm{mm}]}\end{array}$ & $\begin{array}{l}\text { Discontinuity } \\
\text { of the claws }\end{array}$ & $\begin{array}{l}\text { Length } \\
\text { of the } \\
\text { claws } \\
\text { [mm] }\end{array}$ & $\begin{array}{c}\text { Identical } \\
\text { half- } \\
\text { protections }\end{array}$ & $\begin{array}{c}\text { Hole at the } \\
\text { connection } \\
\text { level }\end{array}$ & $\begin{array}{c}\text { Intumescent } \\
\text { joint }\end{array}$ \\
\hline 1 & HEB140 & 134 & 30 & 1 & No & 12 & No & No & No \\
\hline 2 & HEB140 & 134 & 30 & 1 & No & 12 & No & No & Yes \\
\hline 3 & HEB140 & 134 & 30 & 1 & Yes & 12 & No & No & Yes \\
\hline 4 & HEB100 & 161 & 50 & 1 & Yes & 6 & No & No & Yes \\
\hline 5 & HEB140 & 134 & 30 & 0.5 & Yes & 8 & Yes & No & No \\
\hline 6 & HEB140 & 134 & 30 & 0.5 & Yes & 12 & Yes & Yes & No \\
\hline 7 & HEM220 & 64 & 45 & 0.5 & Yes & 12 & Yes & Yes & No \\
\hline
\end{tabular}

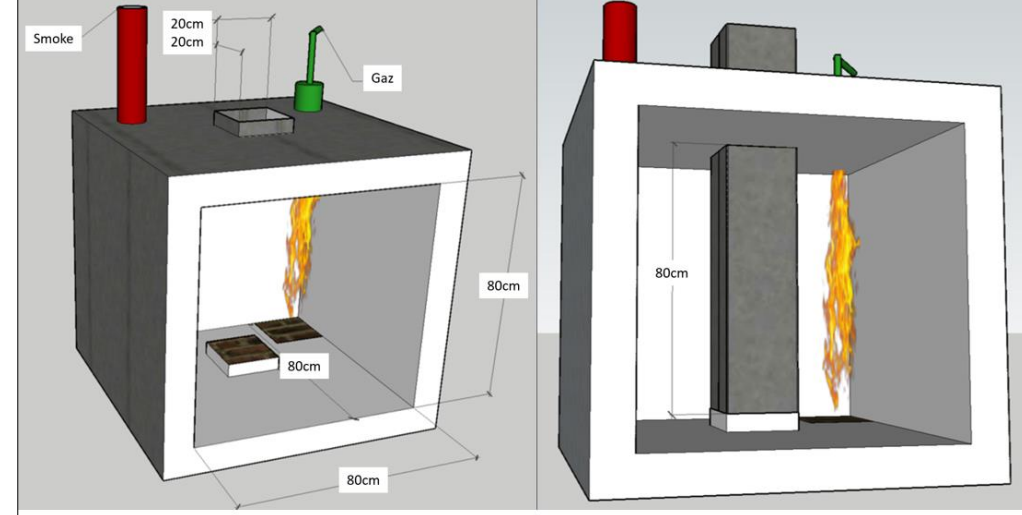

(a)

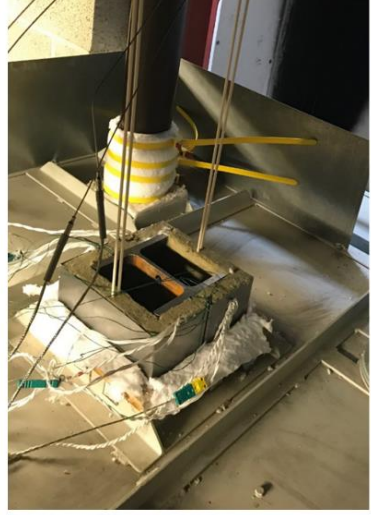

(b)

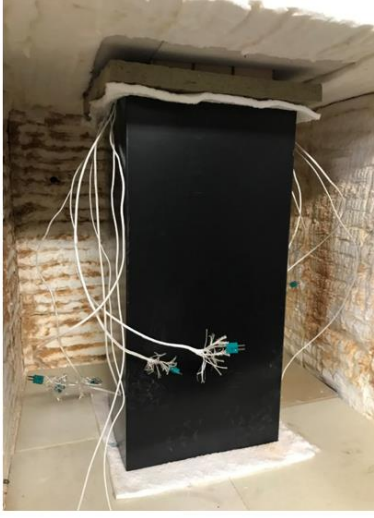

(c)

Figure 7 - Small-scale experimental furnace: a) Dimensions of the furnace; b) HEB140 inserted through the top opening; c) HEM220 inserted through the door

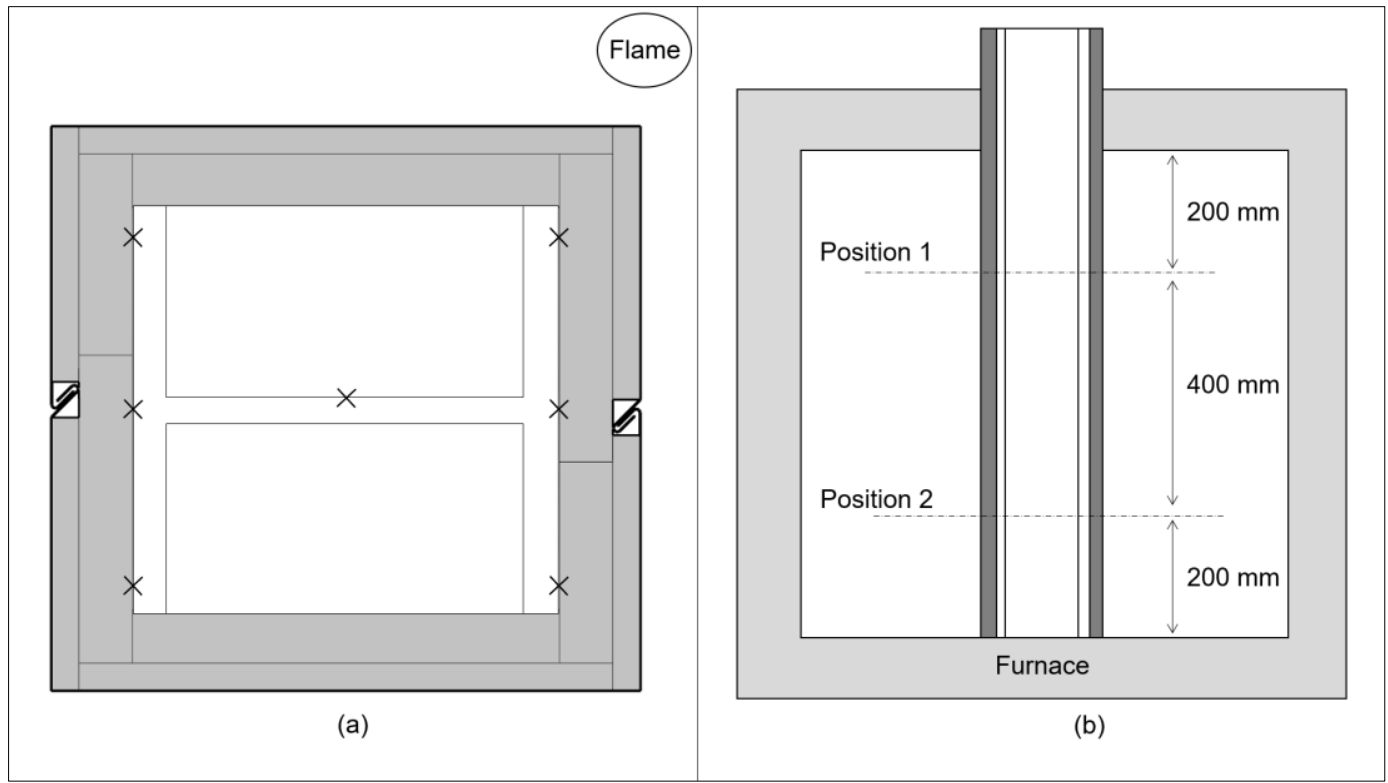

Figure 8 - Thermocouple locations: a) Plan view; b) Transversal view 


\subsection{Experimental observations and results}

For each of the seven specimens, the mean temperature evolution with time recorded by thermocouples set at $200 \mathrm{~mm}$ and $600 \mathrm{~mm}$, are depicted in Figure 9. For all of them except Specimen 7, it was observed that thermocouples set at $200 \mathrm{~mm}$ recorded more severe temperature evolutions than thermocouples set at $600 \mathrm{~mm}$. The first reason is the geometry of the furnace and the downward orientation of the flame. The inferior part of the columns could be exposed to higher temperatures and recorded therefore higher heating rates. The second reason is the fact that for six out of the seven tests, the top opening of the furnace was sealed by the specimen itself. That could constitute a cooling source for the specimens which explains these thermal gradients. Collecting all the curves on the same graph, Figure 9 shows that Specimens 1, 2, 3, and 5, all having almost the same geometry, followed similar temperature evolutions during the whole test. Specimen 4 presented an abnormally high temperature evolution, which was unexpected with numerical predictions based on theoretical value (see Section 0). It was supposed that there were thermal bridges due to manufacturing imperfections. Specimen 6 presented a temperature evolution close to the ones observed by Specimens 1, 2, 3 and 5 during the first hour of test, whereas during the second hour, it reached temperatures around $100{ }^{\circ} \mathrm{C}$ higher. This could be explained by the presence of holes at the levels of the connection claws, which constituted thermal bridges, since the rock wool thickness was reduced to $15 \mathrm{~mm}$. Specimen 7 followed a temperature evolution with time significantly lower than other specimens. That was expected due to the lower section factor of the profile and the 45-mm thick insulation layer. Since the furnace was completely closed, there was during the first hour of test only a small thermal gradient between thermocouples at $200 \mathrm{~mm}$ and $600 \mathrm{~mm}$ due to the flame orientation. After $120 \mathrm{~min}$ of exposure to standard fire, the mean temperatures recorded at 200 $\mathrm{mm}$ and $600 \mathrm{~mm}$ were identical. Considering these observations, the most severe mean temperatures recorded at $200 \mathrm{~mm}$, were used as the basis for the conservative calibrations of the numerical models developed in Sections 0. Although different lengths of the claws were tested ( $6 \mathrm{~mm}, 8 \mathrm{~mm}$ and $12 \mathrm{~mm})$, Figure 10 shows that the seven protection systems remained well connected and closed around the steel profiles during the $120 \mathrm{~min}$ of exposure to standard fire.

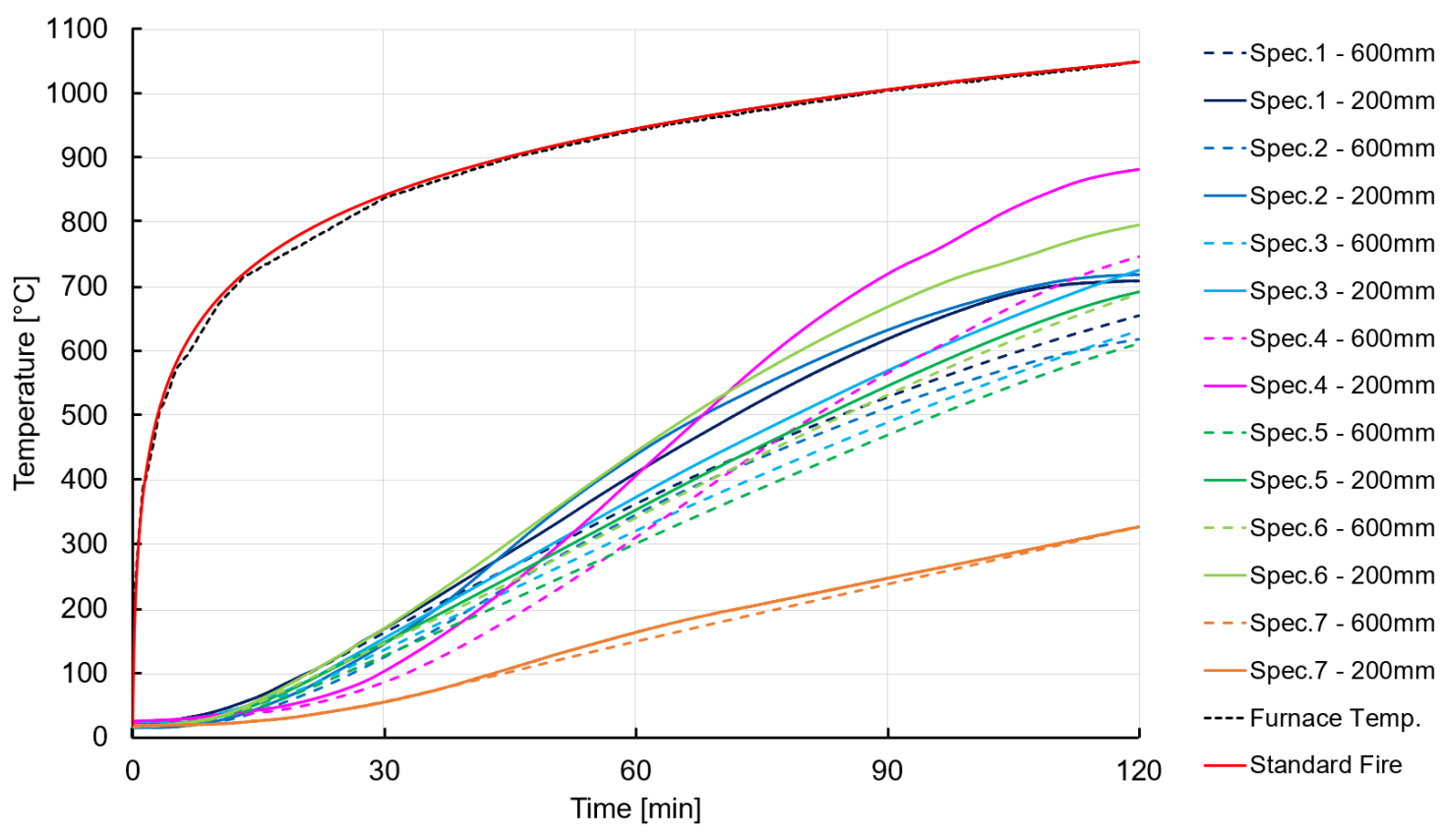

Figure 9 - Small-scale experimental test results - Mean temperatures recorded at $200 \mathrm{~mm}$ and $600 \mathrm{~mm}$ 


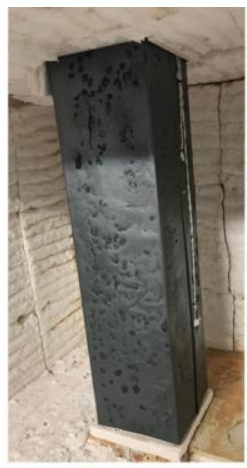

(a)

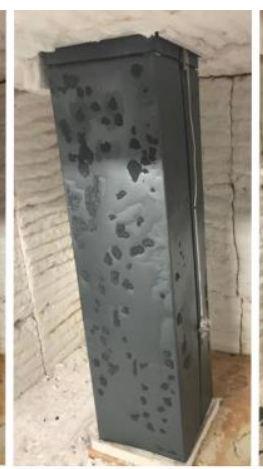

(b)

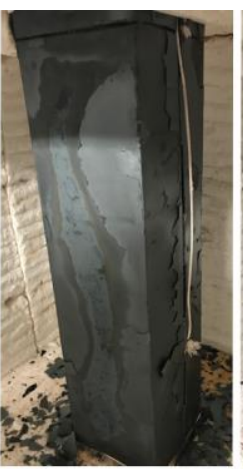

(c)

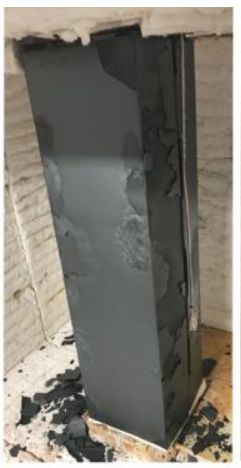

(d)

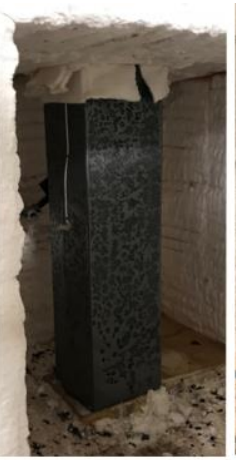

(e)

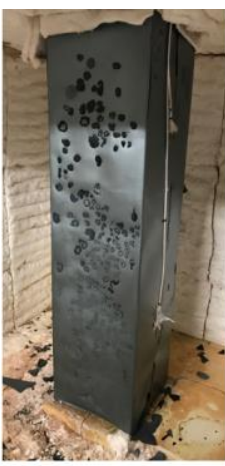

(f)

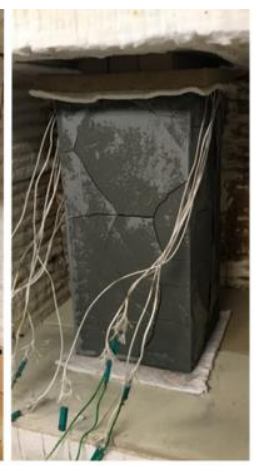

(g)

Figure 10 - Specimens after the 120 min of exposure to standard fire: a) Specimen 1; b) Specimens 2; c) Specimen 3; d) Specimen 4; e) Specimen 5; f) Specimen 6; g) Specimen 7

\section{Numerical and analytical models}

\subsection{D numerical model}

A 3D numerical model was created with the software ABAQUS [28] to study the thermo-mechanical behaviour of the protection. More specifically, the aim of this model was to analyse whether or not the connection claws could disconnect due to steel sheet thermal expansion. Therefore, dynamic implicit procedure was adopted to perform nonlinear analysis. An HEB140 steel profile, protected with $30 \mathrm{~mm}$ of rock wool and a $1 \mathrm{~mm}$ thick steel sheet, was exposed to standard fire for $120 \mathrm{~min}$. The steel profile, the rock wool boards and the steel sheets were modelled with five components discretised with coupled temperature-displacement 3D solid elements, i.e. C3D8T elements [28], using a mesh size of $5 \mathrm{~mm}$. Thermal and mechanical properties of steel, varying with temperature, were defined as prescribed in EN1993-1-2 [24]. Thermal and mechanical properties of rock wool were considered independent of temperature and were provided by the supplier [27] and are summarized in Table 3. Thanks to the symmetry of the protection and the thermal loading condition, being the standard temperature-time curve uniformly applied all around the steel sheet, the analysis could be limited on a half model. For that purpose, appropriated boundary conditions were defined at the symmetrical axis level, as depicted on Figure 11a. The steel profile was fixed along the six directions at the web extremity to stabilize the entire model. The rock wool boards and the steel sheets were free to move vertically but were fixed along the five other directions. Appropriate interactions were defined between the different components to represent the real conditions and geometrical constraints of the protection system. "Tie" constraints were defined between rock wool and steel sheets components. "Hard contact" interactions were defined between steel sheet components and between rock wool and steel profile components. As illustrated in Figure $11 \mathrm{~b}$ and Figure 11c, the five components thermally expanded after the $120 \mathrm{~min}$ of exposure to standard fire. As expected theoretically, the protections thermal expansion was more important than the one of steel profile (up to $2.2 \mathrm{~mm}$ compared to $0.8 \mathrm{~mm}$ ), since they were subjected to a thermal gradient of $1000^{\circ} \mathrm{C}$. Protections displaced relatively to each other, but their claws remained connected. The connection system of the fire protection was designed to present a safe behaviour when heated, so that the thermal expansion of the protections does not tend to disconnect the claws but to keep them closed. This numerical investigation allowed the assessment of this thermal effect. This model reproduced the behaviour of the protection observed with small-scale experimental tests and depicted in Figure 10 where 
specimens remained all well connected around profiles after $120 \mathrm{~min}$ of exposure to standard fire. In a first attempt, this 3D model was developed with a height of $10 \mathrm{~mm}$ to reduce the calculation demand. Since it provided satisfying results, its height was increased to $100 \mathrm{~mm}$ and subsequently to $300 \mathrm{~mm}$. However, no differences were observed, such as steel sheet buckling or claws opening. It was therefore supposed that the thermal expansion of the fire protection, should maintain the claws connected all along the height of the protected column.

Table 3 - Thermal and mechanical properties of rock wool

\begin{tabular}{lccc}
\hline Properties & Symbol & Value & Unit \\
\hline Thermal conductivity & $\lambda_{\mathrm{RW}}$ & 0.20 & {$[\mathrm{~W} / \mathrm{mK}]$} \\
Specific heat & $\mathrm{C}_{\mathrm{RW}}$ & 968 & {$[\mathrm{~J} / \mathrm{kgK}]$} \\
Specific mass & $\rho_{\mathrm{RW}}$ & 160 & {$\left[\mathrm{~kg} / \mathrm{m}^{3}\right]$} \\
Water content & $\mathrm{W}_{\mathrm{RW}}$ & 1.00 & {$\left[\mathrm{~kg} / \mathrm{m}^{3}\right]$} \\
Convection coefficient for hot surface & $\alpha_{\mathrm{c}, \mathrm{hot}}$ & 25.0 & {$\left[\mathrm{~W} / \mathrm{m}^{2} \mathrm{~K}\right]$} \\
Convection coefficient for cold surface & $\alpha_{\mathrm{c}, \mathrm{cold}}$ & 4.00 & {$\left[\mathrm{~W} / \mathrm{m}^{2} \mathrm{~K}\right]$} \\
Relative emissivity & $\varepsilon_{\mathrm{RW}}$ & 0.80 & {$[-]$} \\
Young modulus in compression & $\mathrm{E}_{\mathrm{c}}$ & 0.55 & {$[\mathrm{MPa}]$} \\
\hline
\end{tabular}




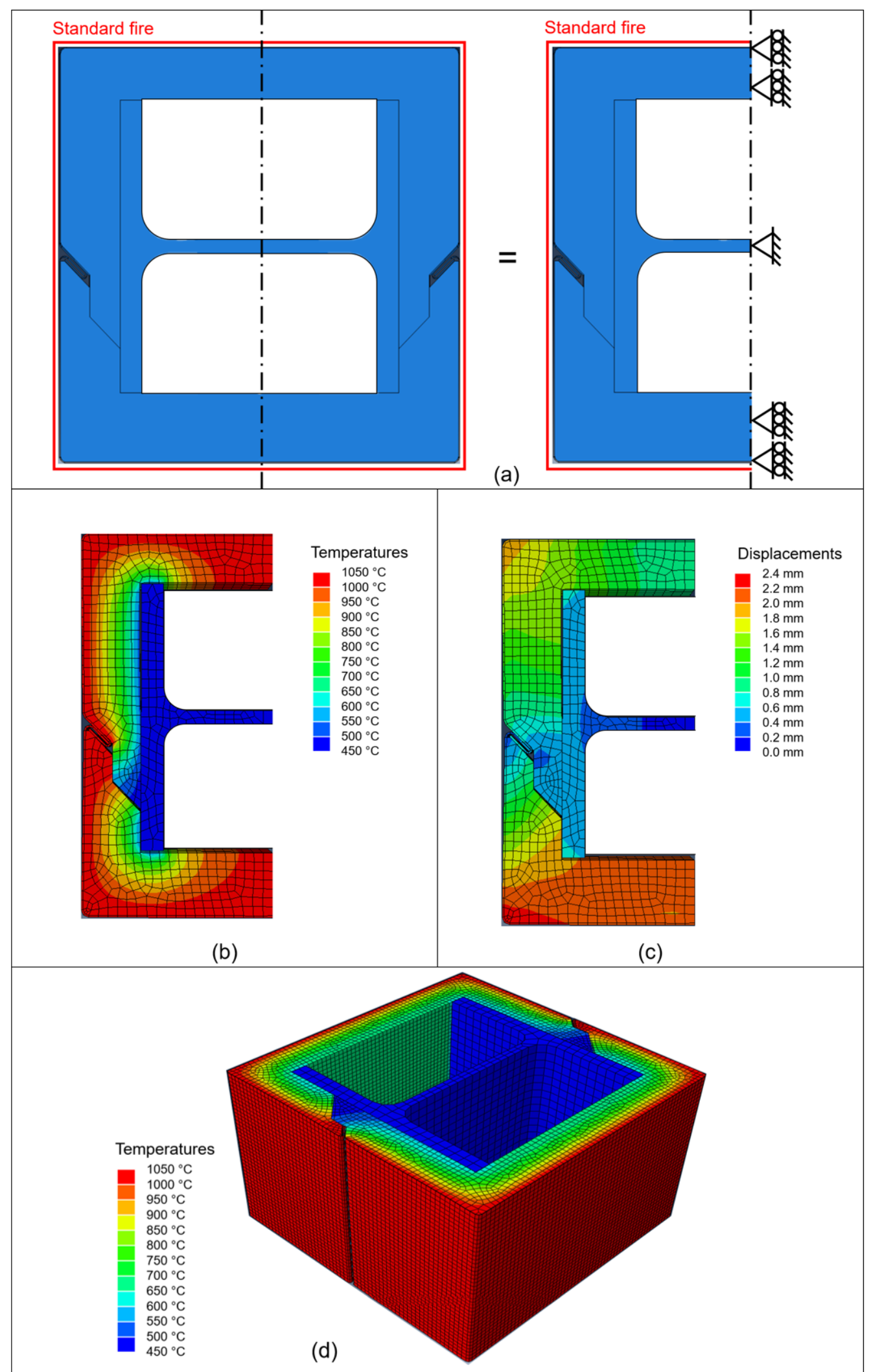

Figure 11 - Abaqus 3D numerical model: a) Numerical model boundary conditions; b) Temperature field within model after 120 min of exposure to standard fire; c) Displacement field within model after 120 min of exposure to standard fire; d) Thermal field in the deformed configuration of the 3D model after $120 \mathrm{~min}$ 


\subsection{D numerical model}

2D numerical models were created with the finite element software SAFIR [29] and calibrated against experimental results to quantify the fire protection thermal efficiency. For that purpose, each specimen cross-section, including the steel profile and the surrounding protection, was discretised with triangular finite elements using a mesh size of $6 \mathrm{~mm}$. These models allowed the accurate geometrical reproduction of the seven specimens and the comparison between experimental- and numerical thermal results. The 2D numerical model corresponding to Specimen 6 is, for instance, depicted in Figure 12a, where the standard temperature-time curve was applied all around the protection. In the same way as for the 3D numerical model, thermal properties used for the rock wool are the ones summarized in Table 3 and thermal properties of steel are taken from EN 1993-1-2 [24]. Figure 12b illustrates the temperature field in Specimen 6 after 120 min of exposure to standard fire. The graph depicted in Figure 13a shows for each Specimen the maximum temperature evolution observed within finite elements discretising steel profiles. Maximum temperatures obtained numerically are intentionally compared with average temperatures observed experimentally to subsequently calibrate numerical models in a conservative way. For Specimens 1, 2, 3, 4 and 6, numerical predictions based on theoretical values provided lower temperature evolutions with time than experimental ones. This can be explained by the thermal dilatation of the protection which is not considered in this numerical model, and by manufacturing imperfections of the specimens. Indeed, imprecision in the cut of boards could generate thermal bridges at some points. For Specimen 5, numerical predictions appeared to coincide with experimental results. For Specimen 7, although the presence of holes around the connection claws, the numerical prediction provided a more conservative temperature evolution with time than the experimental one. That can be linked to its lower section factor and its higher protection thickness.

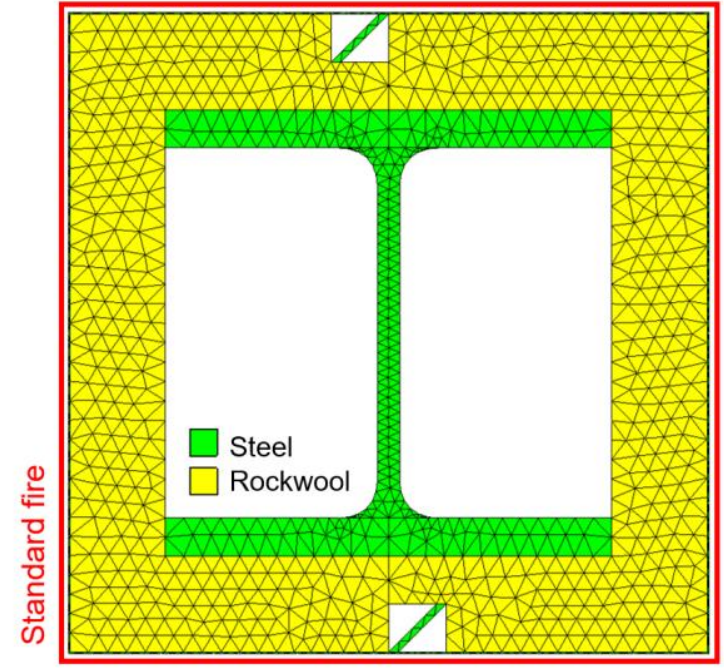

(a)

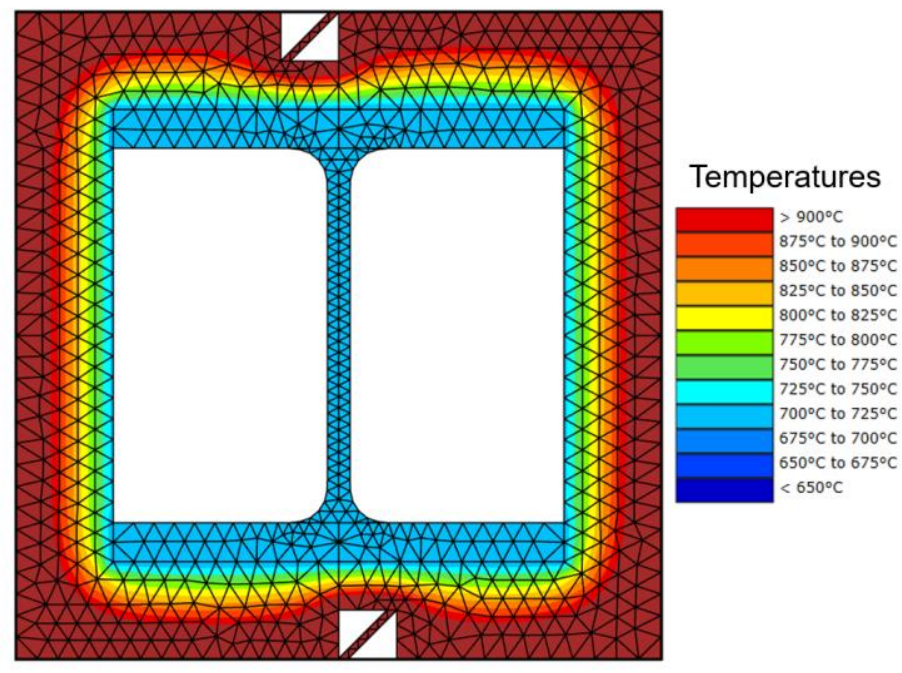

(b)

Figure 12 - 2D numerical model of Specimen 6: a) Cross-section discretisation with a mesh size of $6 \mathrm{~mm}$; b) Temperature field within cross-section after 120 min of exposure to standard fire

In order to take into account these differences observed between numerical predictions and experimental results, the rock wool thermal conductivity (TC) value was calibrated for each specimen with a coefficient $\mathrm{C}_{\text {Num.i. }}$ Calibrating this parameter was convenient since it has a direct influence on the protection thermal 
efficiency. For each specimen $\mathrm{i}$, the theoretical TC value $\lambda_{R W}$ was multiplied by the proper coefficient $\mathrm{C}_{\text {Num.i, }}$ as defined in Eq. (1), so that numerical models provided more conservative (or more optimized for Specimen 7) temperature evolutions with time than experimental ones. This is illustrated on the graph in Figure $13 \mathrm{~b}$. For each specimen, the coefficients $\mathrm{C}_{\text {Num.i }}$ and the corresponding calibrated TC values $\lambda_{\text {Num. }}$ are listed in Table 4.

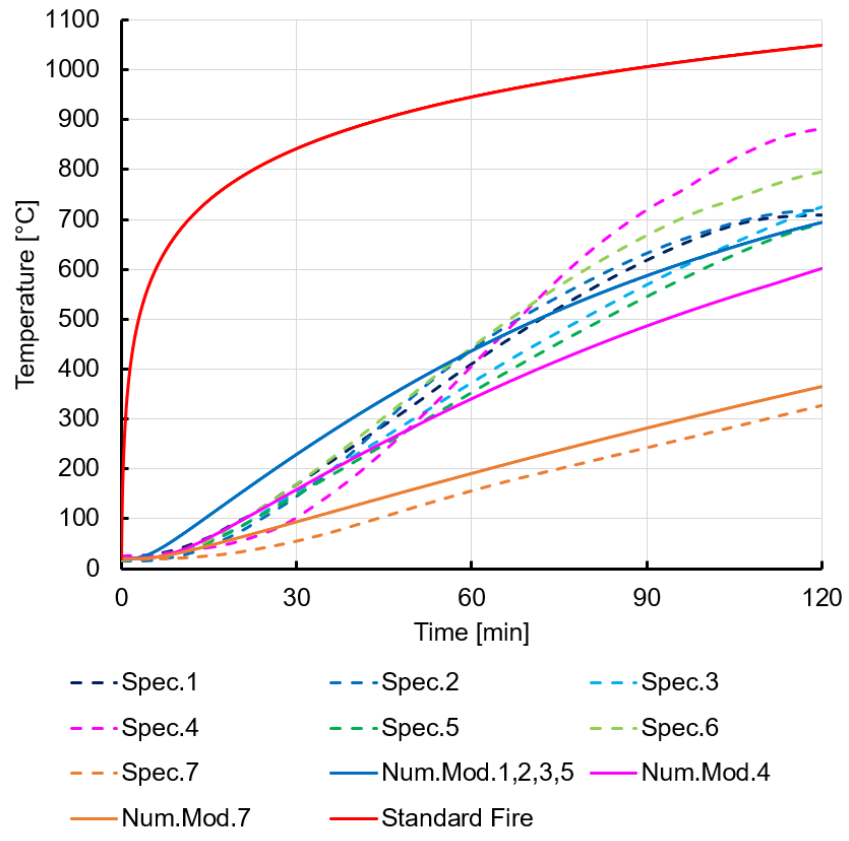

(a)

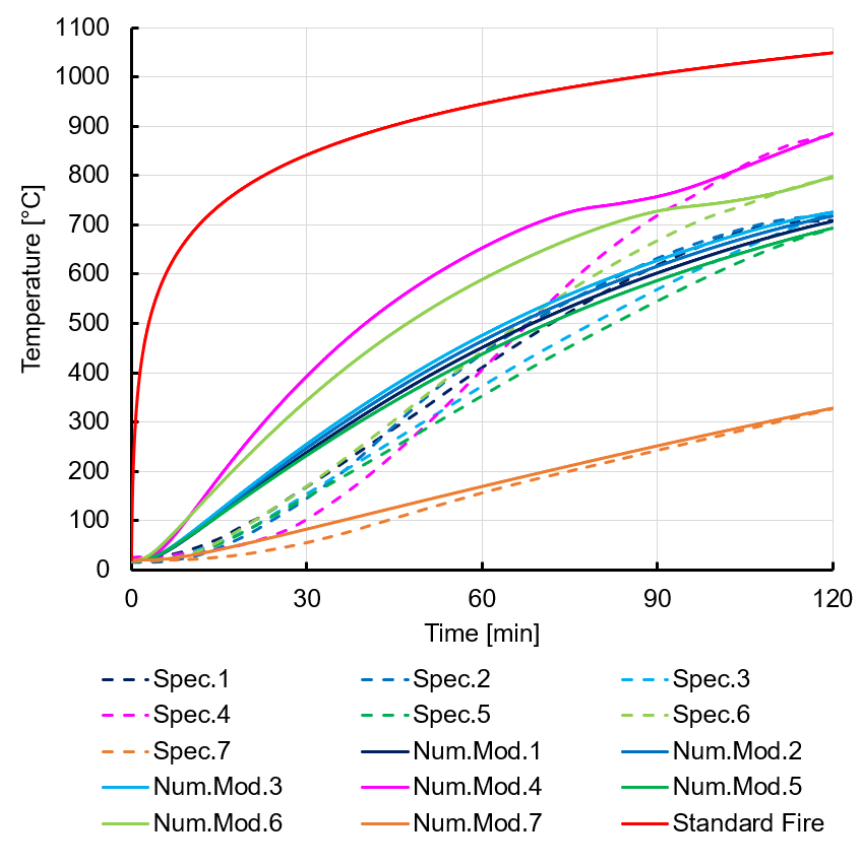

(b)

Figure 13 - Experimental- and numerical temperature evolutions with time using: a) theoretical TC value $\lambda_{R W}$; b) calibrated TC values $\lambda_{\text {Num.i }}$

$$
\lambda_{\text {Num.i }}=\mathrm{c}_{\text {Num.i }} \cdot \lambda_{\mathrm{RW}} \quad[\mathrm{W} / \mathrm{mK}]
$$

Table 4 - List of coefficients and calibrated thermal conductivity values with 2D numerical models

\begin{tabular}{ccccccc}
\hline Specimen & Profile & $\begin{array}{c}\text { Box section } \\
\text { factor }\end{array}$ & $\begin{array}{c}\text { Protection } \\
\text { thickness }\end{array}$ & $\begin{array}{c}\text { Theoretical } \\
\text { thermal } \\
\text { conductivity }\end{array}$ & $\begin{array}{c}\text { Calibration } \\
\text { coefficient }\end{array}$ & $\begin{array}{c}\text { Calibrated } \\
\text { thermal } \\
\text { conductivity }\end{array}$ \\
\hline 1 & HEB140 & 134 & 30 & 0.20 & 1.060 & 0.212 \\
2 & HEB140 & 134 & 30 & 0.20 & 1.115 & 0.223 \\
3 & HEB140 & 134 & 30 & 0.20 & 1.165 & 0.233 \\
4 & HEB100 & 161 & 50 & 0.20 & 3.100 & 0.620 \\
5 & HEB140 & 134 & 30 & 0.20 & 1.000 & 0.200 \\
6 & HEB140 & 134 & 30 & 0.20 & 1.770 & 0.354 \\
7 & HEM220 & 64 & 45 & 0.20 & 0.860 & 0.172 \\
\hline
\end{tabular}


It can be observed that, five out of the seven small-scale experimental tests delivered results that were close from numerical predictions, while two of them presented significantly higher temperature evolutions with time. For Specimens 1, 2, 3, 5 and 7, TC values calibrated with Eq. (1) varied from -14\% to $+16.5 \%$ with respect to the theoretical value. Specimen 6 presented a TC value $77 \%$ higher than the theoretical one. The holes around the connection claws, constituting thermal bridges, should have been highlighted by the 2D numerical model. Although that was not the case, it is important to take that result into consideration to encompass the thermal effects of the holes. Specimen 4 presented a TC value 310\% higher than the theoretical one. That important contrast with numerical predictions is assumed coming from significant manufacturing defects. That result was therefore disregarded.

Based on TC values calibrated with 2D numerical models, the average value and standard deviation could be computed neglecting the value of Specimen 4, as expressed in Eq. (2) and Eq. (3) (where i is not assigned with the value 4). In guidelines for proper application of the norm EN1990 [30], it is recommended to define thermal characteristics by considering either the average value $\lambda_{\text {avg }}$ or the $50^{\text {th }}$ fractile of a beta distribution, $\lambda_{\beta, 50 \%}$. With average TC value $\lambda_{\text {avg }}$ and standard deviation $\sigma$, it was possible to compute parameters $\alpha$ and $\beta$ defining the beta distribution characterising TC values. The $50^{\text {th }}$ fractile was computed from that beta distribution and expressed in Eq. (4).

$$
\begin{array}{ll}
\lambda_{\text {avg }}=\frac{\sum_{\mathrm{i}=1}^{7} \lambda_{\text {Num }, \mathrm{i}}}{6}=0.232 & {[\mathrm{~W} / \mathrm{mK}]} \\
\sigma=\sqrt{\frac{\sum_{\mathrm{i}=1}^{7}\left(\lambda_{\text {Num }, \mathrm{i}}-\lambda_{\text {avg }}\right)^{2}}{6}}=0.058 & {[-]} \\
\lambda_{\beta, 50 \%}=0.229 & {[\mathrm{~W} / \mathrm{mK}]}
\end{array}
$$

It can be observed that the average TC value $\lambda_{\text {avg }}$ and the $50^{\text {th }}$ fractile obtained with the beta distribution $\lambda_{\beta, 50 \%}$ present very close values. Nevertheless, since $\lambda_{\text {avg }}$ appeared slightly more conservative than $\lambda_{\beta, 50 \%}$, it was decided to consider the average TC value to predict the fire protection thermal efficiency. Therefore, Figure 14 depicts temperature evolutions with time obtained with numerical models when applied with the average TC value. It has to be noted that only one curve was plotted for Specimens 1, 2, 3, 5 and 6 because the numerical models applied with $\lambda_{\text {avg }}$ value provided highly similar temperature evolutions with time (difference of $5^{\circ} \mathrm{C}$ to $10^{\circ} \mathrm{C}$ after $120 \mathrm{~min}$ ). For all the Specimens, it can be observed that numerical models provided temperature evolutions with time higher than the experimental ones when applied with $\lambda_{\text {avg }}$ value. However, for Specimen 6, that evolution was lower than experimental results between 75 and $120 \mathrm{~min}$, with difference in order of $7.5 \%$.

Eventually, the development and calibration of 2D numerical models based on experimental results permitted the definition of an average TC values $\lambda_{\text {avg. }}$. The use of this value facilitated reasonable predictions of the fire protection thermal efficiency when applied with the $2 \mathrm{D}$ numerical models 


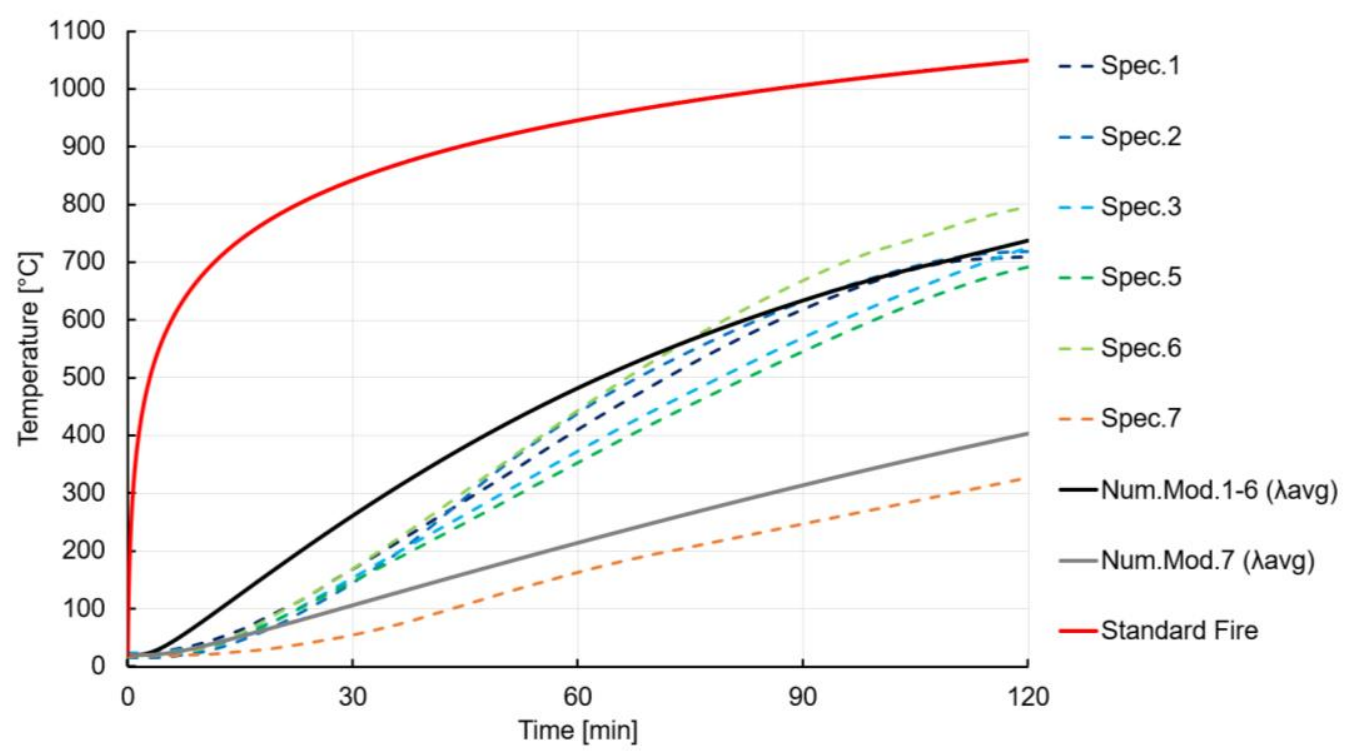

Figure 14 - Experimental- and numerical temperature evolutions with time using average TC value $\lambda_{\text {avg }}$

\subsection{Analytical model}

This section uses the analytical model prescribed in EN1993-1-2 [24] to check its ability to predict the temperature evolution in the steel profile by assuming the calibrated value of the TC identified in the previous section. This analytical model calculates the temperature evolution with time of a protected steel profile, having its four sides exposed to any temperature variation. This method, based on a mass lumped approach, is convenient to use thanks to its low calculation demand. However, its simplistic geometry limits the range of its application. As depicted in Figure 15, the model only considers a single and uniform insulation layer. Therefore, specimens cannot be faithfully represented with the steel sheet surrounding the rock wool layer and the irregularities around connection levels. The analytical formula expressing the temperature evolution with time of a protected steel profile is defined in Eq. (5), where $\phi$ is the amount of heat stored in the protection as expressed in Eq. (6).

$$
\begin{aligned}
& \Delta \theta_{\mathrm{a}}(\mathrm{t})=\frac{\lambda_{\mathrm{p}} \mathrm{A}_{\mathrm{p}} / \mathrm{V}}{\mathrm{d}_{\mathrm{p}} \mathrm{c}_{\mathrm{a}} \rho_{\mathrm{a}}} \cdot \frac{\left(\theta_{\mathrm{g}}(\mathrm{t})-\theta_{\mathrm{a}}(\mathrm{t})\right)}{\left(1+\frac{\phi}{3}\right)} \Delta \mathrm{t}-\left(\mathrm{e}^{\phi / 10}-1\right) \Delta \theta_{\mathrm{g}}(\mathrm{t})\left[{ }^{\circ} \mathrm{C}\right] \\
& \phi=\frac{\mathrm{c}_{\mathrm{p}} \cdot \mathrm{d}_{\mathrm{p}} \cdot \rho_{\mathrm{p}}}{\mathrm{c}_{\mathrm{a}} \cdot \rho_{\mathrm{a}}} \cdot \frac{\mathrm{A}_{\mathrm{p}}}{V}
\end{aligned}
$$

In the same manner as for numerical models, the evolution with time of the gas temperature $\theta_{\mathrm{g}}(\mathrm{t})$ followed the standard fire curve, and thermal properties considered for steel and rock wool materials, are the ones from EN1993-1-2 and the ones listed in Table 3, respectively. Similarly to the observations made with 2D numerical models, Figure 16a shows that the analytical model, when applied with theoretical values, provided for all the specimens except the $7^{\text {th }}$ one, lower temperature evolutions with time than experimental ones. For the specimen 7, the analytical model also predicted a higher temperature evolution with time than the experimental one. Figure $16 \mathrm{~b}$ depicts temperature evolutions with time obtained with the analytical model when applied with the average TC values $\lambda_{\text {avg }}$ computed in the previous section. Results are similar to the ones observed with 2D numerical models. Analytical model provided a temperature evolution with time close from the experimental ones when applied with $\lambda_{\text {avg, }}$ for Specimens 
1, 2, 3, 5, whereas for Specimen 6, that evolution was lower than the experimental result after 70 min. For specimen 7 , the temperature evolution obtained with $\lambda_{\text {avg }}$ was higher than experimental results. Globally the analytical model allowed the assessment of the TC values calibrated with the 2D numerical model. It could be observed that both numerical and analytical models provided similar results. The average TC values $\lambda_{\text {avg }}$ was therefore considered in Section 5 as indicator for the definition of the largescale experimental campaign.

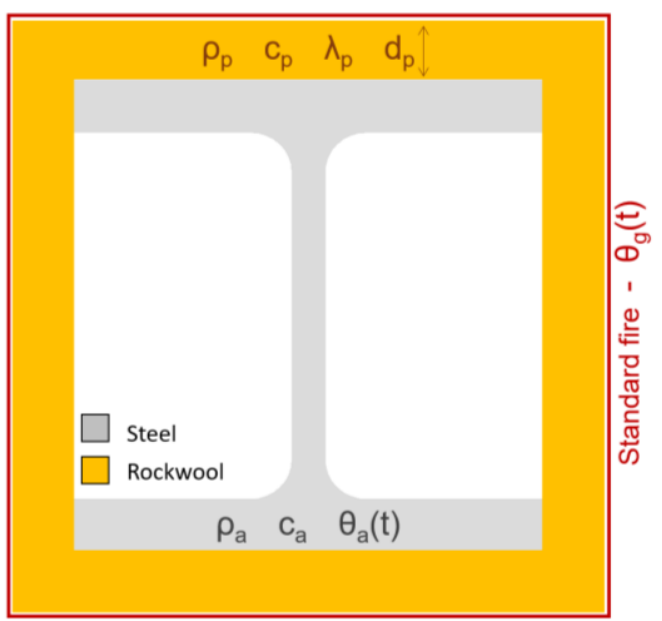

Figure 15 - Representation of the cross-section with the analytical model

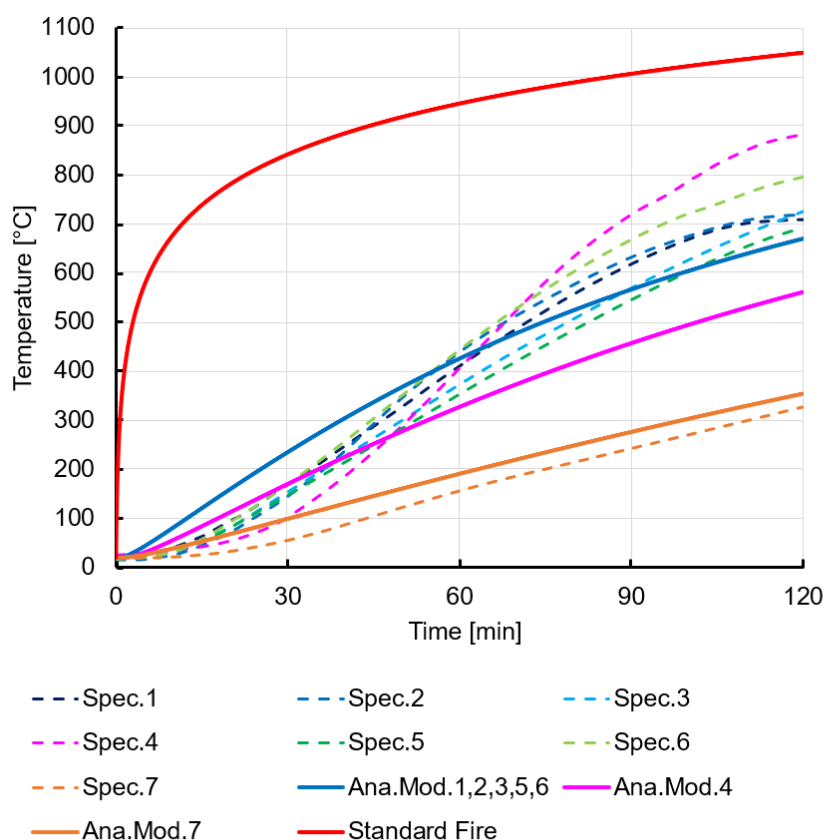

(a)
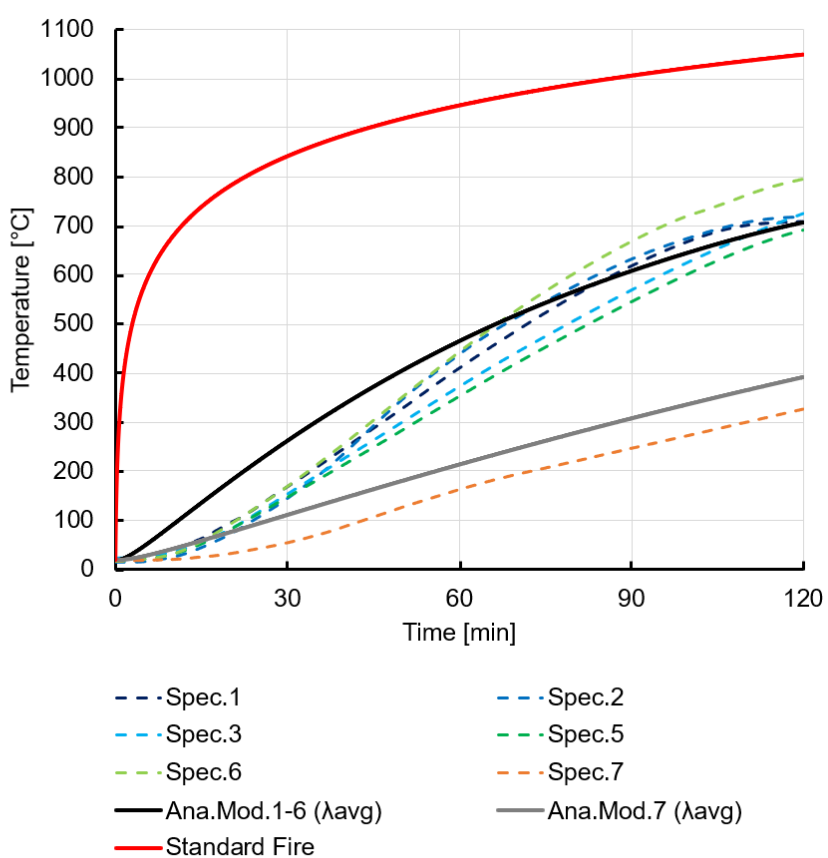

(b)

Figure 16 - Experimental- and analytical temperature evolutions with time using: a) theoretical TC value $\lambda_{R W}$; b) average TC values $\lambda_{\text {avg }}$ 


\subsection{Predictions with the regression model}

An alternative method to assess and predict the efficiency of a fire protection based on experimental test results can be found in Annex E.3 of the European norm EN13381-4 [25]. In this method, for a predefined steel design temperature $\theta_{a}$, the TC value to be used with different protection geometries, is defined as a function of the thickness of the protection $d_{p}[m]$ and the box section factor $A_{p} / V\left[m^{-1}\right]$ of the protected profile. This function is obtained by linear regression, as expressed in Eq. (7).

$$
\lambda_{\theta a}\left(A_{p} / V, d_{p}\right)=a_{0}+a_{1} \cdot A_{p} / V+a_{2} \cdot d_{p} \quad[W / m K]
$$

The coefficients $a_{0}, a_{1}$ and $a_{2}$ are found by applying the least squares method with the TC values determined with the analytical model based on experimental results. For design temperatures in the range of $350^{\circ} \mathrm{C}$ to $600^{\circ} \mathrm{C}$ with step equal to $50^{\circ} \mathrm{C}$, coefficients $a_{0}, a_{1}$ and $a_{2}$ can be defined by using the data of all the Specimens except for Specimen 4. For each Specimen, considering the recorded times to reach design temperatures it was straightforward to determine the corresponding TC values using the analytical model with Eq. (5) depicted in section 4.3. For each Specimen, times to reach the different design temperatures and the corresponding TC values are summarised in

Table 5 - Times for specimens to reach design temperatures

\begin{tabular}{|c|c|c|c|c|c|c|c|c|c|}
\hline \multicolumn{10}{|c|}{ Time [min] } \\
\hline \multirow{2}{*}{ Specimen } & \multirow{2}{*}{ Profile } & \multirow{2}{*}{$\begin{array}{c}\text { Box section } \\
\text { factor } A_{p} / V\left[m^{-1}\right]\end{array}$} & \multirow{2}{*}{$\begin{array}{l}\text { Thickness } d_{p} \\
{[\mathrm{~mm}]}\end{array}$} & \multicolumn{6}{|c|}{ Design temperatures $\theta_{\mathrm{a}}\left[{ }^{\circ} \mathrm{C}\right]$} \\
\hline & & & & 350 & 400 & 450 & 500 & 550 & 600 \\
\hline 1 & HEB140 & 134 & 30 & 53 & 59 & 65 & 72 & 79 & 87 \\
\hline 2 & HEB140 & 134 & 30 & 50 & 56 & 61 & 68 & 76 & 84 \\
\hline 3 & HEB140 & 134 & 30 & 57 & 64 & 71 & 79 & 87 & 95 \\
\hline 5 & HEB140 & 134 & 30 & 60 & 67 & 75 & 83 & 91 & 99 \\
\hline 6 & HEB140 & 134 & 30 & 50 & 55 & 61 & 67 & 73 & 80 \\
\hline 7 & HEM 220 & 64 & 45 & 129 & 147 & 165 & 176 & $186^{*}$ & $195 *$ \\
\hline
\end{tabular}

*time extrapolated based on experimental results

and Table 6, respectively. It has to be noted that for Specimen 7, the times to reach $550^{\circ} \mathrm{C}$ and $600^{\circ} \mathrm{C}$ were estimated based on experimental results by linear extrapolation. Subsequently, for each design temperature, coefficients $a_{0}, a_{1}$ and $a_{2}$ were defined by linear regression using the TC values corresponding to each specimen. Eventually, these coefficients are defined in Table 7 for each design temperature and computed with Eq. (7). In this respect, Figure 17 illustrates the function $\lambda_{\theta a}\left(A_{p} / V, d_{p}\right)$ for a design temperature $T_{i}$ equal to $600^{\circ} \mathrm{C}$.

Subsequently, function $\lambda_{\theta a}\left(A_{p} / V, d_{p}\right)$ could be used with the analytical model to evaluate the mean temperature of a protected profile after a time period t. Nevertheless, it must be ensured that the resulting temperature at time $t$ is in accordance with the design temperature $\theta_{a}$ associated to the considered function $\lambda_{\theta a}$. Since a significant difference was observed between Specimens 12356 and Specimen 7 presenting precisely different protection thicknesses and box section factors, this method appeared relevant to be applied here. Table 8 compares the TC values calibrated with the 2D numerical model and the ones predicted here with the regression model. It appeared that the function $\lambda_{\theta a}\left(A_{p} / V, d_{p}\right)$ provided a TC value for Specimens 12356 very close to the average TC value $\lambda_{\text {avg }}(0.2316$ against 0.2320 $[\mathrm{W} / \mathrm{mK}]$ ) and a more conservative TC value for Specimen 7. That function was therefore also considered in Section 5 as indicators for the definition of the large-scale experimental campaign. 
Table 5 - Times for specimens to reach design temperatures

\begin{tabular}{|c|c|c|c|c|c|c|c|c|c|}
\hline \multicolumn{10}{|c|}{ Time [min] } \\
\hline \multirow{2}{*}{ Specimen } & \multirow{2}{*}{ Profile } & \multirow{2}{*}{$\begin{array}{c}\text { Box section } \\
\text { factor } A_{p} / V\left[m^{-1}\right]\end{array}$} & \multirow{2}{*}{$\begin{array}{l}\text { Thickness } d_{p} \\
{[\mathrm{~mm}]}\end{array}$} & \multicolumn{6}{|c|}{ Design temperatures $\theta_{a}\left[{ }^{\circ} \mathrm{C}\right]$} \\
\hline & & & & 350 & 400 & 450 & 500 & 550 & 600 \\
\hline 1 & HEB140 & 134 & 30 & 53 & 59 & 65 & 72 & 79 & 87 \\
\hline 2 & HEB140 & 134 & 30 & 50 & 56 & 61 & 68 & 76 & 84 \\
\hline 3 & HEB140 & 134 & 30 & 57 & 64 & 71 & 79 & 87 & 95 \\
\hline 5 & HEB140 & 134 & 30 & 60 & 67 & 75 & 83 & 91 & 99 \\
\hline 6 & HEB140 & 134 & 30 & 50 & 55 & 61 & 67 & 73 & 80 \\
\hline 7 & HEM220 & 64 & 45 & 129 & 147 & 165 & 176 & $186 *$ & $195 *$ \\
\hline
\end{tabular}

*time extrapolated based on experimental results

Table 6 - TC values corresponding to specimens for each design temperature

\begin{tabular}{cccccccccc}
\hline \multicolumn{10}{c}{ Thermal conductivity value $[\mathrm{W} / \mathrm{mK}]$} \\
\hline \multirow{2}{*}{ Specimen } & Profile & $\begin{array}{c}\text { Box section } \\
\text { factor } A_{\mathrm{p}} / \mathrm{V}\left[\mathrm{m}^{-1}\right]\end{array}$ & $\begin{array}{c}\text { Thickness } \mathrm{d}_{\mathrm{p}} \\
{[\mathrm{mm}]}\end{array}$ & 350 & 400 & 450 & 500 & 550 & 600 \\
\hline 1 & HEB140 & 134 & 30 & 0.173 & 0.185 & 0.199 & 0.210 & 0.223 & 0.236 \\
2 & HEB140 & 134 & 30 & 0.186 & 0.198 & 0.215 & 0.226 & 0.235 & 0.247 \\
3 & HEB140 & 134 & 30 & 0.158 & 0.168 & 0.179 & 0.187 & 0.197 & 0.211 \\
5 & HEB140 & 134 & 30 & 0.149 & 0.158 & 0.166 & 0.175 & 0.186 & 0.200 \\
6 & HEB140 & 134 & 30 & 0.186 & 0.203 & 0.215 & 0.230 & 0.247 & 0.264 \\
7 & HEM220 & 64 & 45 & 0.181 & 0.188 & 0.196 & 0.215 & $0.238^{*}$ & $0.265^{*}$ \\
\hline
\end{tabular}

*TC value determined based on extrapolated time

Table 7 - Regression coefficients

\begin{tabular}{ccccccc}
\hline \multirow{2}{*}{$\begin{array}{c}\text { Regressions } \\
\text { coefficient }\end{array}$} & 350 & 400 & 450 & 500 & 550 & 600 \\
\hline $\mathrm{a}_{0}$ & 0.10374 & 0.10804 & 0.11233 & 0.12350 & 0.13566 & 0.14946 \\
$\mathrm{a}_{1}$ & 0.00016 & 0.00023 & 0.00029 & 0.00023 & 0.00017 & 0.00011 \\
$\mathrm{a}_{2}$ & 1.48399 & 1.45319 & 1.44913 & 1.70899 & 1.97515 & 2.25396 \\
\hline
\end{tabular}




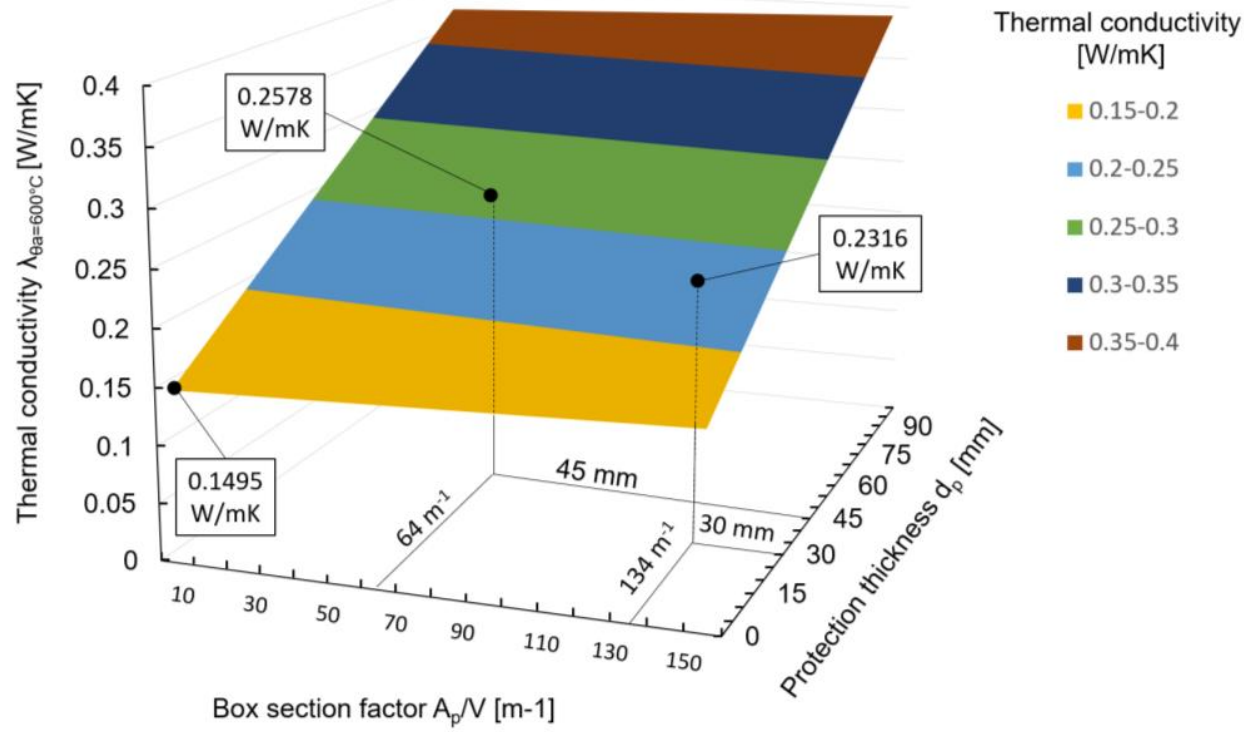

Figure 17 - Definition of $\lambda_{\theta a}\left(A_{p} / V, d_{p}\right)$ for a design temperature $\theta_{a}$ of $600^{\circ} \mathrm{C}$

Table 8 - Comparison between calibrated- and predicted TC values

\begin{tabular}{|c|c|c|c|c|c|c|}
\hline \multicolumn{7}{|c|}{ Thermal conductivity value $[\mathrm{W} / \mathrm{mK}]$} \\
\hline Specimen & Profile & $\begin{array}{c}\text { Box section } \\
\text { factor } A_{p} / V \\
{\left[\mathrm{~m}^{-1}\right]}\end{array}$ & $\begin{array}{c}\text { Thickness } \\
\mathrm{d}_{\mathrm{p}}[\mathrm{mm}]\end{array}$ & $\begin{array}{c}\text { Calibrated TC } \\
\text { values } \lambda_{\text {Num.i }} \\
{[\mathrm{W} / \mathrm{mK}]}\end{array}$ & $\begin{array}{c}\text { Predicted TC values } \\
\lambda_{\theta a}\left(A_{p} / v, d_{p}\right) \\
{[W / m K]}\end{array}$ & $\lambda_{\theta a} / \lambda_{\text {Num.i }}$ \\
\hline 1 & HEB140 & 134 & 30 & 0.212 & 0.2316 & 1.09 \\
\hline 2 & HEB140 & 134 & 30 & 0.223 & 0.2316 & 1.04 \\
\hline 3 & HEB140 & 134 & 30 & 0.233 & 0.2316 & 0.99 \\
\hline 5 & HEB140 & 134 & 30 & 0.2 & 0.2316 & 1.16 \\
\hline 6 & HEB140 & 134 & 30 & 0.354 & 0.2316 & 0.65 \\
\hline 7 & HEM 220 & 64 & 45 & 0.172 & 0.181 & 1.05 \\
\hline
\end{tabular}

\section{Large-scale experimental tests}

\subsection{Objectives}

Small-scale experimental tests and calibrated models described in Section 3 and 4 aimed to assess the potential of the fire protection. Since promising results were observed, it was decided to carry on the fire protection development by performing large-scale experimental fire tests. The execution of theses largescale tests had three objectives:

i) The first objective was to test other protection geometries and to collect additional data and to improve the understanding of the fire protection efficiency. 
ii) The second objective was to study the thermo-mechanical behaviour of the protection in realistic conditions. For that purpose, the protection was installed around a steel column 3.1 $\mathrm{m}$ high and vertically loaded to $60 \%$ of its load bearing capacity. In such conditions, possible column flexural buckling characterised by out-of-plane displacements could affect the insulation efficiency of the protection by generating excessive stresses within the connection claws and consequently causing thermal bridges.

iii) The third objective of these large-scale experimental tests was to certify a final version of the fire protection, according to the European norm EN13381-4 [25]. This norm addresses passive fire protection systems preventing the heating of structural steel members (columns and beams) when exposed to standard fire, and it provides the experimental procedure to be adopted. For fires protection systems made of boards and addressing steel columns, the norm prescribes a "test package" to certify the protection when applied with any thicknesses, around any profiles, for one fire resistance. Nevertheless, this "test package" requires the successful experimental tests of 15 specimens, 2 loaded columns and 13 unloaded columns. Considering the stage of the protection development and the important costs of experimental tests, the scope of this large-scale experimental campaign was limited to the certification of one single version of the protection. The final version of the protection developed here, presents one insulation thickness and addresses a limited range of profiles, aiming to maintain their temperature below $550^{\circ} \mathrm{C}$ after $120 \mathrm{~min}$ of exposure to standard fire. In the framework of the present work, the number of specimens to test was therefore reduced to 5 specimens, 1 loaded column and 4 unloaded columns.

\subsection{Final version of the fire protection system}

Before the large-scale experimental tests and the subsequent assessment according to the European norm EN13381-4 [25] had to be selected. All the features of the final protection version results from smallscale experimental tests described in Section 3. They are listed here below and emerged based on observations made during the specimen manufacturing process and on considerations regarding installation ease and costs.

Absence of intumescent joint - Initially, it was planned to use intumescent joints at the connection level to ensure insulation in case of thermal bridge due to the thermal expansion of the protections. Eventually, it appeared unnecessary since specimens 1, 2, 3 and 5 presented all very similar thermal results whereas Specimens 1 and 5 had no intumescent joint.

Discontinuity of rock wool boards - Finally, instead of using intumescent joints at connection levels, proper discontinuity of rock wool boards at connection level was found to be a measure efficient enough to mitigate potential thermal bridges. Therefore, the total insulation layer thickness of the final protection version must be composed of two boards facilitating the creation of discontinuities at connection levels and within the corner as depicted in Figure 2.

Discontinuity of male claws - Based on observations made with small-scale experimental tests, the discontinuity of male claws significantly made the protection installation easier without presenting any issues in terms of thermal and mechanical resistance. 
Square holes around connection claws - It is the unwilling result from an optimised fabrication process. Since it is much more convenient to shape rock wool boards with rectangular sections, it was decided to fill the total thickness of the rock wool with the use of two boards. The exterior board presents a fixed thickness of $15 \mathrm{~mm}$, which corresponds to the depth of the claw inside the protection. The thickness of the interior board is set to $30 \mathrm{~mm}$. Consequently, the final version of the protection presents a total rock wool thickness of $45 \mathrm{~mm}$. However, in further developments of the fire protection, the thickness of the interior board could be affected by any value depending on the targeted fire resistance. The negative thermal impact of the hole at the connection level is mitigated by the rock wool board discontinuity.

Steel sheet thickness - The thickness of the steel sheet composing the protection structure was set to 0.7 $\mathrm{mm}$. Preliminary tests demonstrated that using a thickness of $0.5 \mathrm{~mm}$ or $1 \mathrm{~mm}$ led for both cases to conclusive thermal results. However, during prototype development, it appeared that $0.5 \mathrm{~mm}$ thick steel sheets were more subjected to plastic deformations in case of physical blow. On the other hand, using 1 $\mathrm{mm}$ thick steel sheets led to excessive weight and undue costs. With these considerations, a thickness of $0.7 \mathrm{~mm}$ was selected. Furthermore, it can be shown with numerical analyses that the use of thinner steel sheets (i.e. $0.5 \mathrm{~mm}$ ) generates more vulnerable thermal effects than the use of thicker ones (i.e. $1 \mathrm{~mm}$ ). It means that the protection system developed in this paper with thickness of $0.7 \mathrm{~mm}$ could be safely fabricated and used with steel sheets presenting higher thicknesses but not thinner ones.

Length of the connection claws - Different lengths of claws were tried with preliminary tests such as 6 $\mathrm{mm}, 8 \mathrm{~mm}$ and $12 \mathrm{~mm}$. The objective was to facilitate the installation of the protection around a column by reducing the length of the claws. However, since the forces to be applied remained important, it was decided to the keep the original length of $12 \mathrm{~mm}$ to prevent claws disconnection in case of significant thermal expansion.

\subsection{Specimens and instrumentation}

Five specimens were tested in the fire laboratory at the University of Liège, Belgium. This laboratory is accredited to deliver European certifications based on experimental results. The properties of the five specimens are defined in the Table 9 and their geometries are depicted in Figure 18 and Figure 19. As defined in previous Section, the final version of the fire protection presents a rock wool thickness of 45 $\mathrm{mm}$, composed of two boards of $15 \mathrm{~mm}$ and $30 \mathrm{~mm}$ and surrounded by a $0.7 \mathrm{~mm}$ thick steel sheet, and there are square holes around the connection claws. This geometry is identical to the one of Specimen 7 tested in the small-scale experimental campaign. Before the test, the five specimens were arranged in the furnace with appropriate thermal boundary conditions. As illustrated in Figure 20a, to make quasiadiabatic boundary conditions at the top and bottom of the unloaded specimens, they were laid on 30 $\mathrm{mm}$ thick rockwool boards and $25 \mathrm{~mm}$ of ceramic fibre. The top of the specimens was covered with ceramic fibre and a rock wool board, on which a brick of cellular concrete was applied to minimise thermal bridges. Regarding the loaded specimen, the steel plates welded at its extremities for the proper load application, were wrapped with ceramic fibre to minimise heat transfer (Figure 20b). Additionally, for the five specimens, $30 \mathrm{~mm}$ thick rock wool boards were inserted between the flanges at the top and bottom of the profiles (Figure 20c). Each fire protection was properly installed around steel profiles. However, two claws were disconnected at the top of the loaded column and they remained too hard to connect, as illustrated in Figure 20d. This was due to excessive thickness of rock wool resulting from manufacturing defect. 
Table 9 - Properties of the large-scale experimental tests

\begin{tabular}{|c|c|c|c|c|c|c|c|c|c|c|c|}
\hline Specimen & Profile & $\begin{array}{l}\text { Height } \\
\text { [m] }\end{array}$ & $\begin{array}{l}\text { Loaded / } \\
\text { Unloaded }\end{array}$ & $\begin{array}{c}\text { Box } \\
\text { section } \\
\text { factor } \\
{\left[\mathrm{m}^{-1}\right]}\end{array}$ & $\begin{array}{c}\text { Rock } \\
\text { wool } \\
\text { thickness } \\
{[\mathrm{mm}]}\end{array}$ & $\begin{array}{c}\text { Steel } \\
\text { sheet } \\
\text { thickness } \\
{[\mathrm{mm}]}\end{array}$ & $\begin{array}{l}\text { Discontinuity } \\
\text { of the claws }\end{array}$ & $\begin{array}{c}\text { Claws } \\
\text { length } \\
{[\mathrm{mm}]}\end{array}$ & $\begin{array}{l}\text { Identical } \\
\text { half- } \\
\text { protections }\end{array}$ & $\begin{array}{c}\text { Hole at the } \\
\text { connection } \\
\text { level }\end{array}$ & $\begin{array}{c}\text { Intumescent } \\
\text { joint }\end{array}$ \\
\hline 8 & HEB240 & 1.0 & Unloaded & 94 & 45 & 0.7 & Yes & 12 & Yes & Yes & No \\
\hline 9 & HEB320 & 1.0 & Unloaded & 80 & 45 & 0.7 & Yes & 12 & Yes & Yes & No \\
\hline 10 & HEM220 & 1.0 & Unloaded & 64 & 45 & 0.7 & Yes & 12 & Yes & Yes & No \\
\hline 11 & HEM400 & 1.0 & Unloaded & 46 & 45 & 0.7 & Yes & 12 & Yes & Yes & No \\
\hline 12 & HEM220 & 3.1 & Loaded & 64 & 45 & 0.7 & Yes & 12 & Yes & Yes & No \\
\hline
\end{tabular}
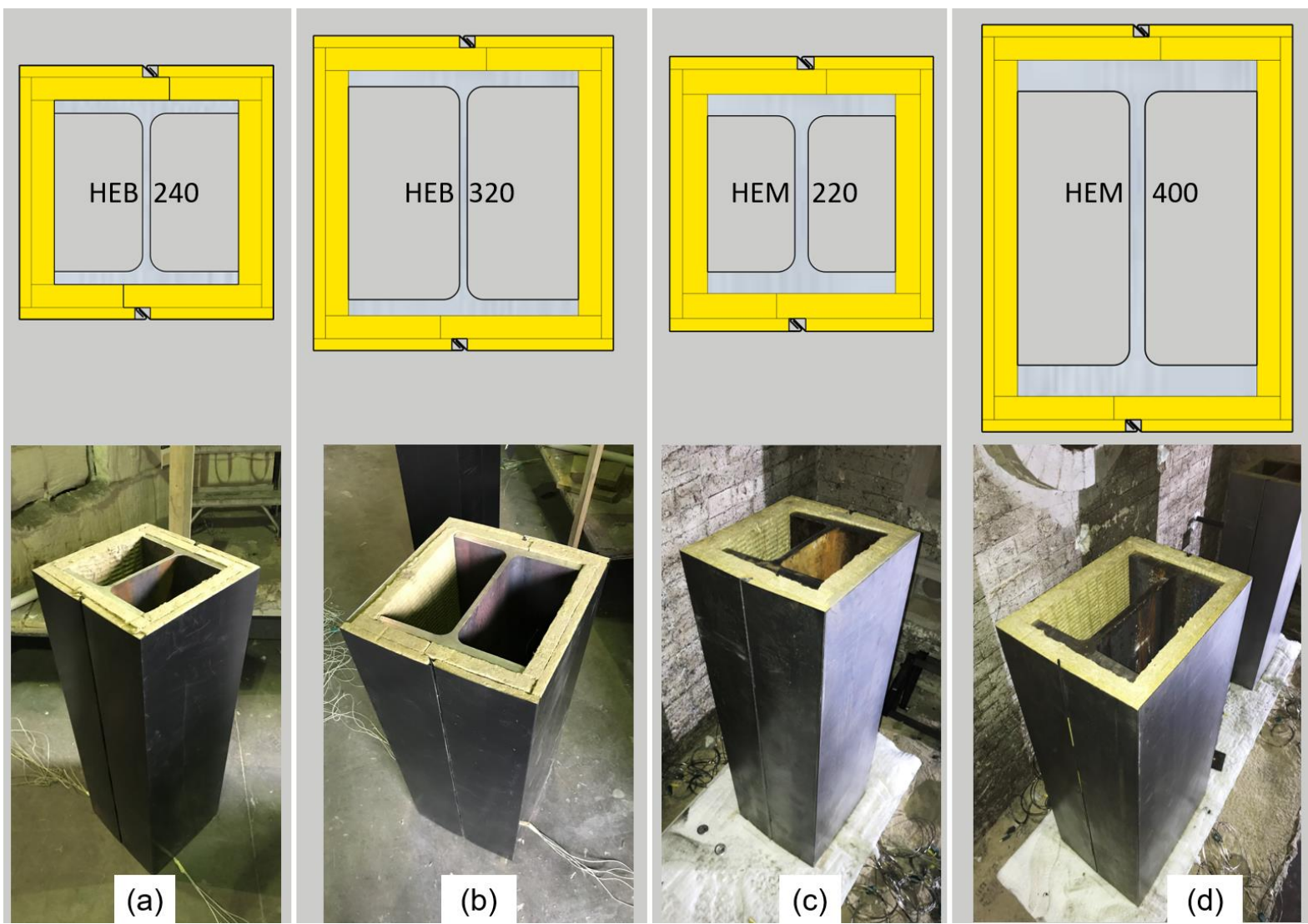

Figure 18 - Description of the unloaded specimens: a) Specimen 8; b) Specimen 9; c) Specimen 10; d) Specimen 11 

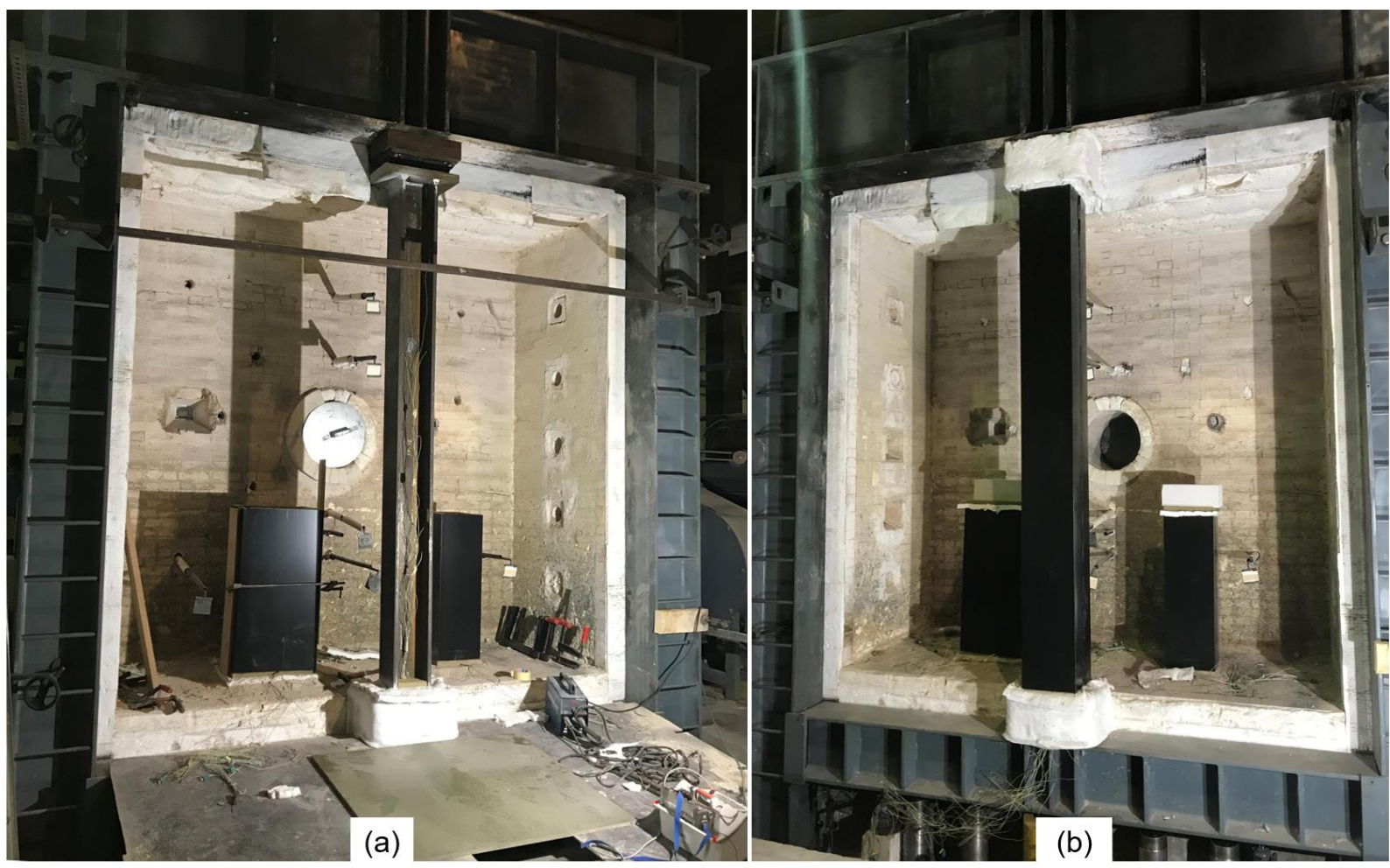

Figure 19 - Description of the loaded specimen 12: a) unprotected; b) Protected

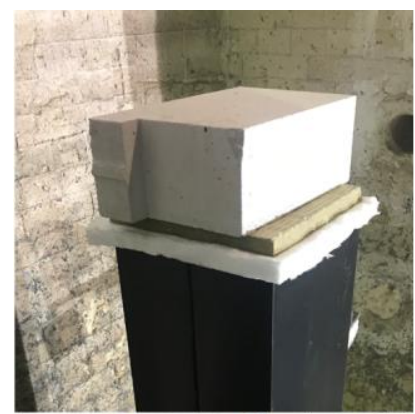

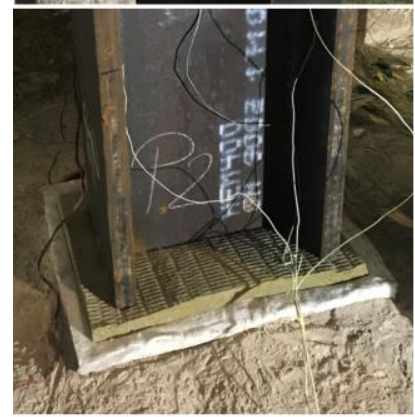

(a)

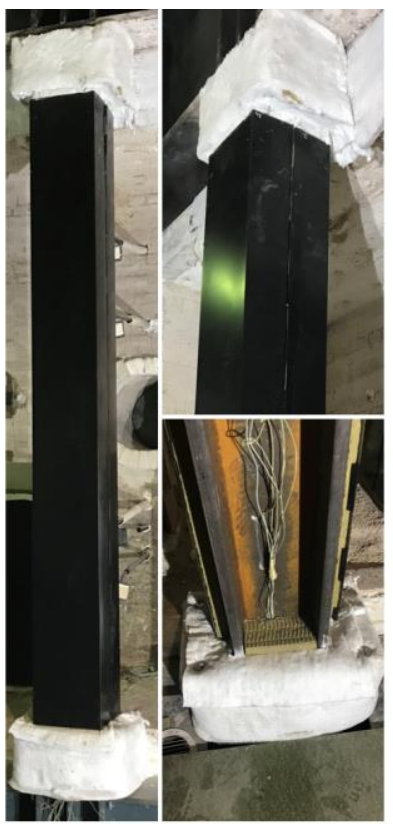

(b)

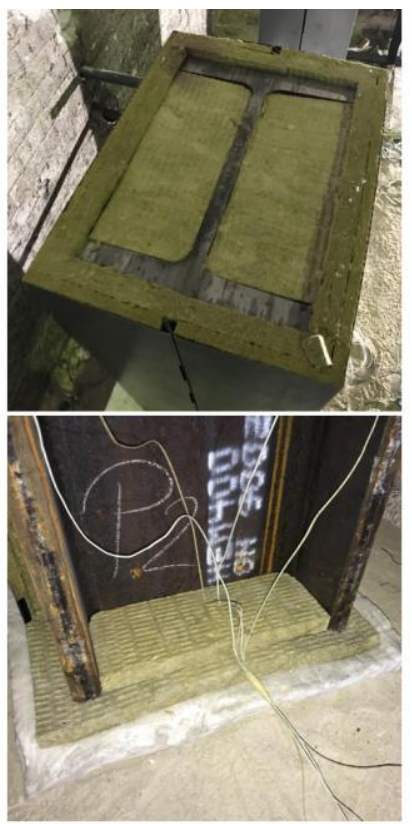

(c)

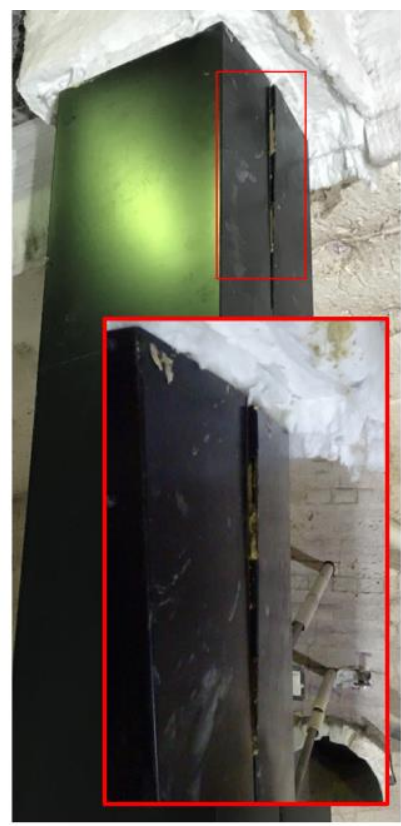

(d)

Figure 20 - Details of specimens: a) Boundary conditions of unloaded specimens; b) Boundary conditions of the loaded specimen; c) Rock wool boards between steel profile flanges; d) Disconnection of two claws

The protection was designed for columns of buildings requiring a fire resistance period of 120 min (R120), that can be found in several common occupancies, such as hotels, office buildings, schools, public buildings, etc. The values of TC obtained in Section 4.2 and 4.4 , i.e. $\lambda_{\text {avg }}$ and $\lambda_{\theta a}\left(A_{p} / V, d_{p}\right)$, were used to estimate the temperature of each profile equipped with a protection thickness of $45 \mathrm{~mm}$ after $120 \mathrm{~min}$ of 
exposure to the standard fire. These temperature predictions are plotted in Figure 21, as a function of the box section factor of the protected profile. Considering the type of columns which usually requires a R120 fire protection, the range of profiles addressed by the final version of the protection, was limited to box section factor values in the range of $46 \mathrm{~m}^{-1}$ and $94 \mathrm{~m}^{-1}$. That represents $\mathrm{HE}$ steel profiles of section from HEM400 to a HEB240, respectively. The temperature of an HEB240 equipped with the protection after 120 min of exposure to standard fire, was estimated to $493^{\circ} \mathrm{C}$ and $480^{\circ} \mathrm{C}$ with the use of $\lambda_{\text {avg }}$ and $\lambda_{500^{\circ} \mathrm{C}}\left(A_{p} / V, d_{p}\right)$, respectively. These temperatures were more than $10 \%$ below $550^{\circ} \mathrm{C}$ which constituted a margin for unforeseen thermal results in large-scale tests. HEB240 steel profile was therefore selected as the upper limit in term of box section factor. Additionally, it is not relevant to protect steel profiles for which the ratio between the protection thickness and the profile depth presents too high values. Based on these predictions, HEB240, HEB320, HEM220 and HEM400 S355 steel profiles were selected to be the unloaded specimens. According to the norm, the loaded steel profile must be selected among the unloaded ones. That allows thermal efficiency comparison of two identical protections, when applied to loaded and unloaded columns. This comparison is detailed in Section 6.1. Furthermore, the loaded profile cannot be the one presenting the minimum or the maximum section factor. Therefore, an HEM220 S355 steel profile $3.1 \mathrm{~m}$ high was selected to be the loaded specimen. The norm requires the concentric application of a vertical point load equivalent to $60 \%$ of the load bearing capacity of the column which corresponds to a load of $2505 \mathrm{kN}$ in accordance with EN 1993-1-1 [31]. Two $50 \mathrm{~mm}$ thick steel plates were welded at the column extremities to distribute the load on the entire cross-section area. The loaded specimen was installed at the centre of the furnace within a steel frame controlled by two actuators. Boundary conditions of the loaded specimen were pinned-pinned about the weak axis and fixed-fixed about the strong axis, as required by the norm.

The scale of these experimental tests is considered as "large" due to the dimensions of the experimental furnace, which allowed the simultaneous performance of the five experimental tests. The arrangement of the specimens is illustrated with a plan view in Figure 22a and respected the distance of separation prescribed by the norm as the maximum value between $300 \mathrm{~mm}$ and the depth of the protected profile. The steel frame loading Specimen 12 is illustrated in Figure 22b, with the two displacement sensors located at the extremities of the beam applying the load. The four unloaded specimens were identically instrumented with 9 thermocouples. As depicted in Figure 23a, 4 thermocouples were set at $500 \mathrm{~mm}$ from the bottom and 5 set at $800 \mathrm{~mm}$. The loaded specimen was instrumented with 15 thermocouples. As depicted in Figure 23b, 5 thermocouples were set at $1033 \mathrm{~mm}, 2067 \mathrm{~mm}$ and $2900 \mathrm{~mm}$ from the bottom. 


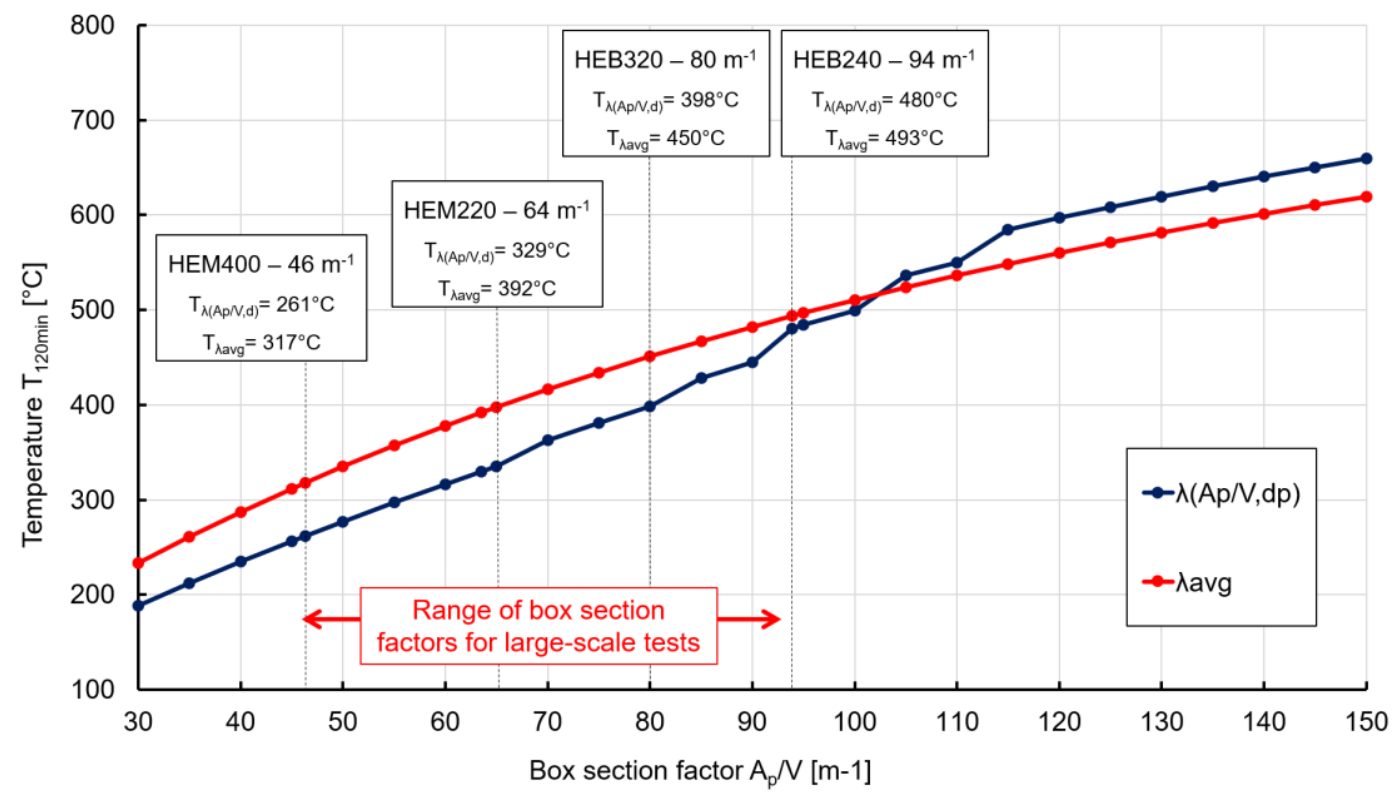

Figure 21 - Temperature predictions for profiles protected with $45 \mathrm{~mm}$ after $120 \mathrm{~min}$ of exposure to standard fire

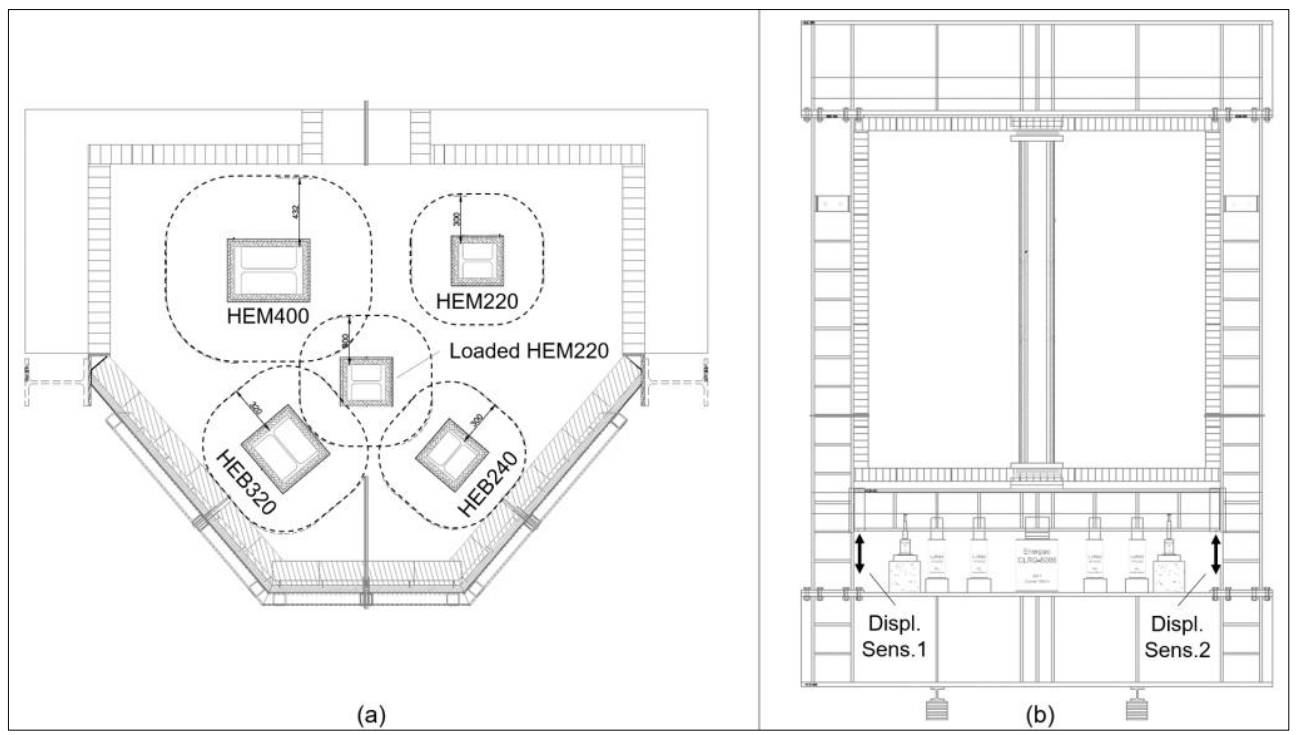

Figure 22 - Large-scale experimental furnace: a) plan view; b) transversal view 


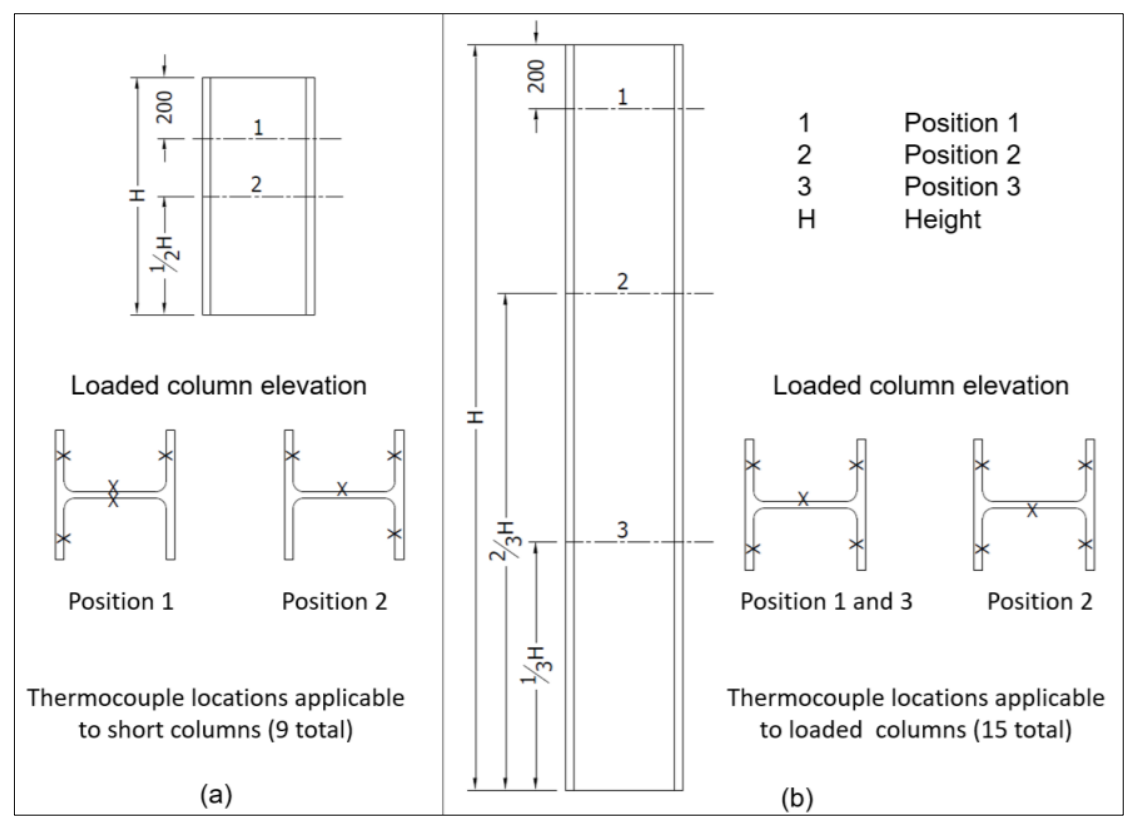

Figure 23 - Thermocouples locations issued by the Norm EN13381-4: a) Unloaded specimens; b) Loaded specimen

\subsection{Experimental observations and results}

Overall mean steel temperature evolutions with time resulting from the five specimens are depicted in Figure 24. These temperatures result from the sum of the mean temperatures recorded at each level of thermocouples divided by the number of levels. For each specimen, mean temperatures recorded at each level of thermocouples are plotted in Figure 25 to highlight thermal gradients within the specimens.

Regarding unloaded profiles, i.e. Specimens 8, 9, 10 and 11, they exhibited temperature evolutions with time that were higher for profiles presenting higher section factors. For each of them, it could be noticed that thermocouples located at $800 \mathrm{~mm}$ from the bottom, recorded slightly higher temperatures (+/- 13 ${ }^{\circ} \mathrm{C}$ ) than thermocouples located at $500 \mathrm{~mm}$. Overall mean temperatures recorded after $120 \mathrm{~min}$ of exposure to standard fire, for Specimens $8,9,10$ and 11 , were $398^{\circ} \mathrm{C}, 358^{\circ} \mathrm{C}, 334^{\circ} \mathrm{C}$ and $245^{\circ} \mathrm{C}$, respectively. For the four specimens, after $190 \mathrm{~min}$ of exposure to the standard fire it was observed that protections were intact, and their connection claws remained closed as exposed in Figure 27.

Regarding the loaded profile, i.e. Specimen 12, it exhibited different temperature-time evolutions at the three levels of thermocouples. In fact, thermocouples located at $2900 \mathrm{~mm}$ recorded significantly higher temperature evolutions with time than the ones located at $2067 \mathrm{~mm}$ and $1033 \mathrm{~mm}$. This was due to the two claws which remained open. After 120 min of exposure to standard fire, mean temperatures recorded at $2900 \mathrm{~mm}, 2067 \mathrm{~mm}$ and $1033 \mathrm{~mm}$ were respectively $538^{\circ} \mathrm{C}, 394^{\circ} \mathrm{C}$ and $343^{\circ} \mathrm{C}$, generating an overall mean temperature of $425^{\circ} \mathrm{C}$. This temperature was $27.3 \%$ higher than the one of the unloaded Specimen 10 having the same geometry.

Mechanically, the load of $2505 \mathrm{kN}$ was progressively applied on Specimen 12 in 15 min and was maintained then for 20 min before the furnace was switched on. The evolution with time of the axial displacement of the column is plotted in Figure 26 and defined in equation Eq. (8) as the sum of the thermal expansion, expressed in Eq. (9) and the mechanical one. As illustrated on the graph, the thermal expansion is considered positive since it tends to increase the height of the profile while the axial displacement owing to mechanical loading is considered negative. 


$$
\begin{array}{ll}
\Delta \mathrm{L}_{\text {Tot }}(\mathrm{t})=\Delta \mathrm{L}_{\text {Therm. }}(\mathrm{t})+\Delta \mathrm{L}_{\text {Mech. }}(\mathrm{t}) & {[\mathrm{mm}]} \\
\Delta \mathrm{L}_{\text {Therm. }}(\mathrm{t})=\Delta \mathrm{T}(\mathrm{t}) \cdot \alpha \cdot \mathrm{L} & {[\mathrm{mm}]}
\end{array}
$$

With

$$
\Delta \mathrm{T}(\mathrm{t})=\mathrm{T}(\mathrm{t})-\mathrm{T}_{0}
$$

In these equations, $T(t)$ is the overall mean temperature of the loaded profile at the time $t, T_{0}$ is the overall mean temperature of the loaded profile at the beginning of the test, equal to $17^{\circ} \mathrm{C}$. $\alpha$ is the thermal expansion coefficient of steel, equal to $1.2 \times 10^{-5}{ }^{\circ} \mathrm{C}^{-1}$. $\mathrm{L}$ is the height of the loaded profile, equal to $3.1 \mathrm{~m}$. After loading the column attained an axial displacement of $-2.48 \mathrm{~mm}$. After $10 \mathrm{~min}$ of exposure to standard fire, the column started to axially displace with constant rate of $+0.15 \mathrm{~mm} / \mathrm{min}$. This displacement rate was due to thermal expansion of the column and occurred between $10 \mathrm{~min}$ and $130 \mathrm{~min}$, which entailed a total axial displacement of $+19 \mathrm{~mm}$. Only after $138 \mathrm{~min}$ of exposure to standard fire, the column started to buckle at the top level of the specimen, where the average temperature of the column was $604^{\circ} \mathrm{C}$ after $140 \mathrm{~min}$, as illustrated in Figure 28c. In fact, between $138 \mathrm{~min}$ and $146 \mathrm{~min}$, a sudden column shortening was observed and at 146 min the load application was removed.

Besides the two claws disconnected during all the experiment, all the other claws of the protection remained closed around the column during the all test duration. As illustrated in Figure 28, after the experiment, the protection was open at the top with a gap of $+/-4 \mathrm{~cm}$ (Figure 28a), wider than at the beginning of the test namely due to the buckling of the profile (Figure 28c). Moreover, the steel plates composing the protection were buckled at the bottom of the specimen (Figure 28b). This was due to the thermal dilatation prevented by the end plates and due to the weight of the protection.

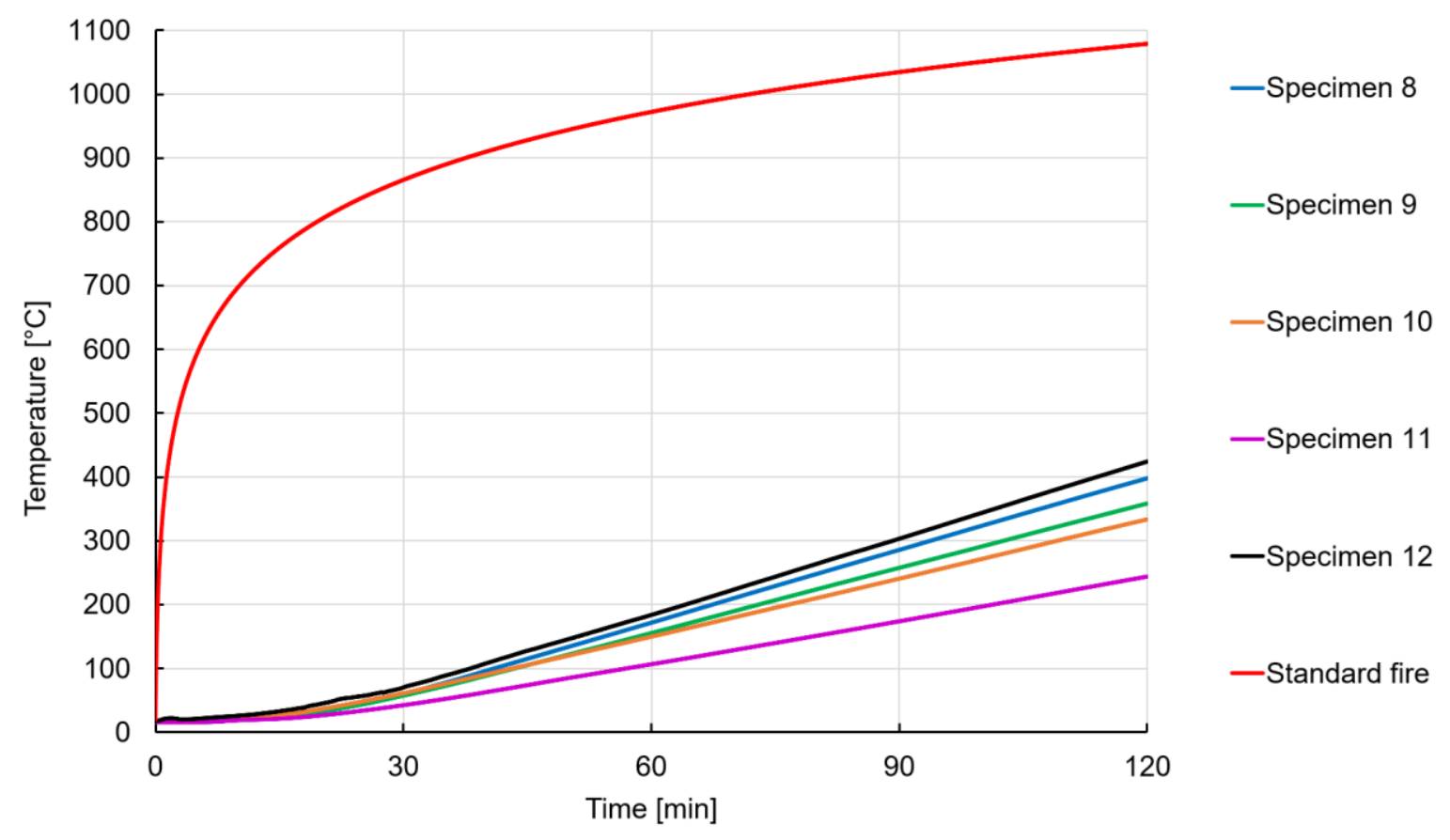

Figure 24 - Large-scale experimental tests results - Overall mean temperature evolutions with time 


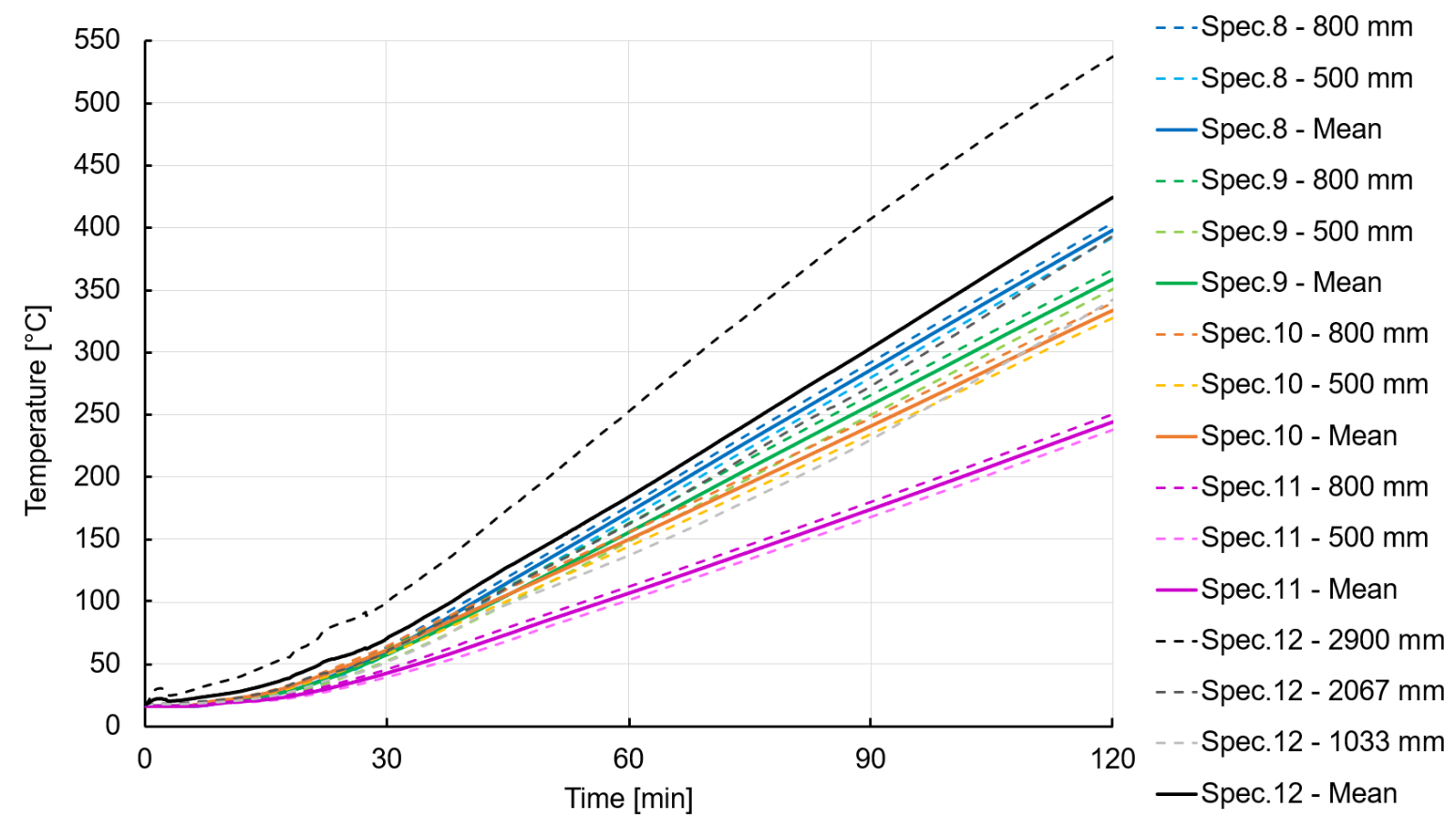

Figure 25 - Large-scale experimental tests results - Mean temperature evolutions with time at each location of thermocouples

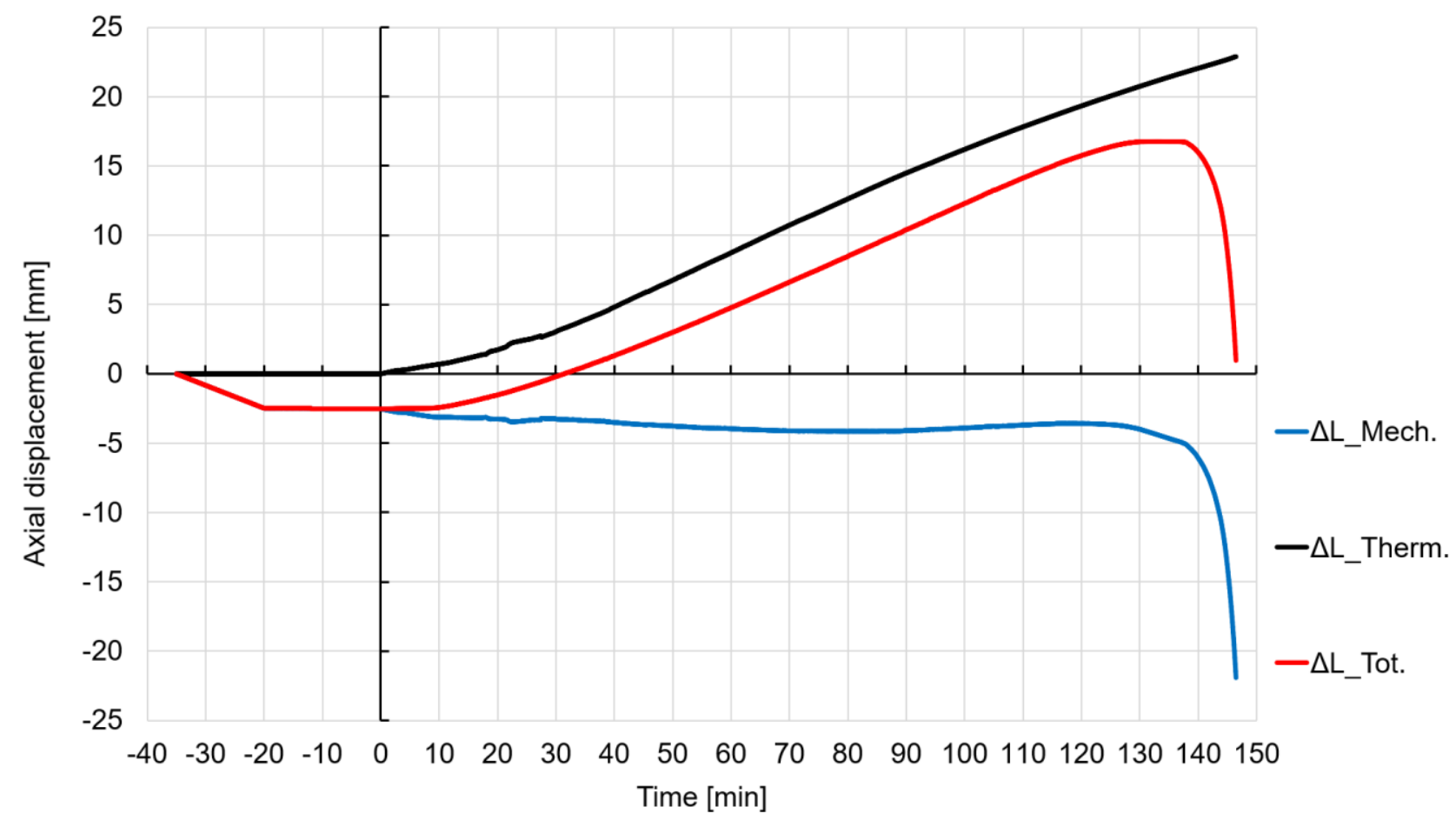

Figure 26 - Large-scale experimental tests results - Axial displacement evolution with time 

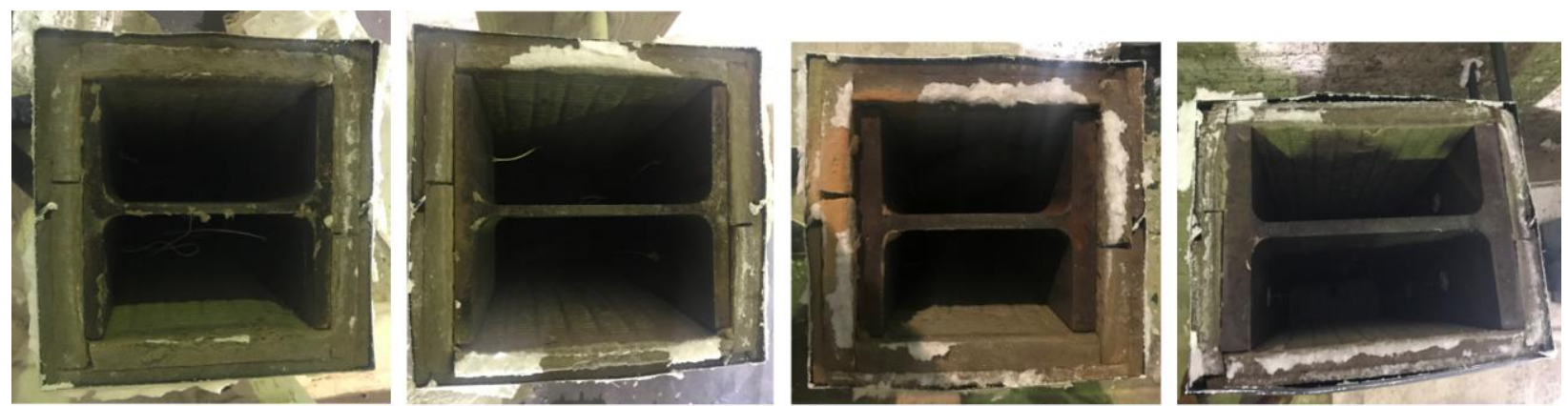

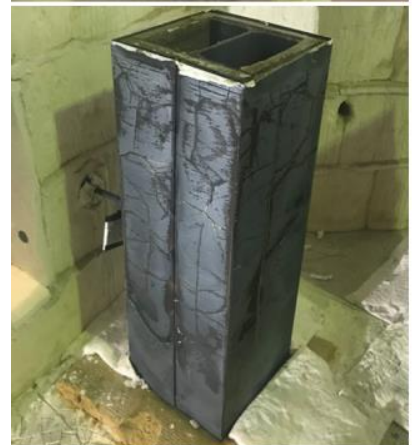

(a)

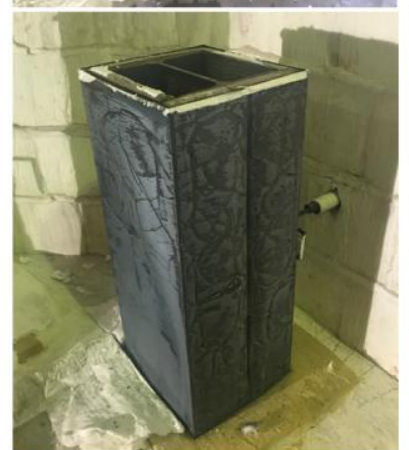

(b)

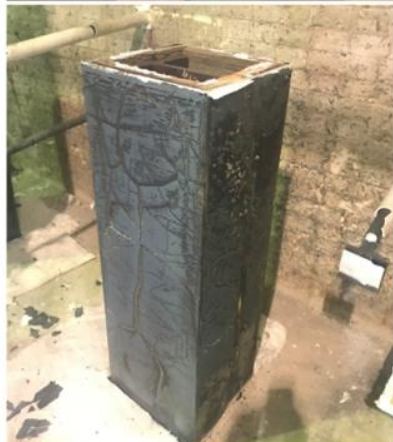

(c)

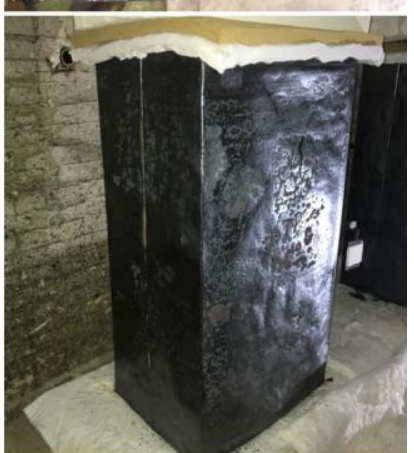

(d)

Figure 27 - Unloaded specimens after the 120 min of exposure to standard fire: a) Specimen 8; b) Specimen 9; c) Specimen 10; d) Specimen 11

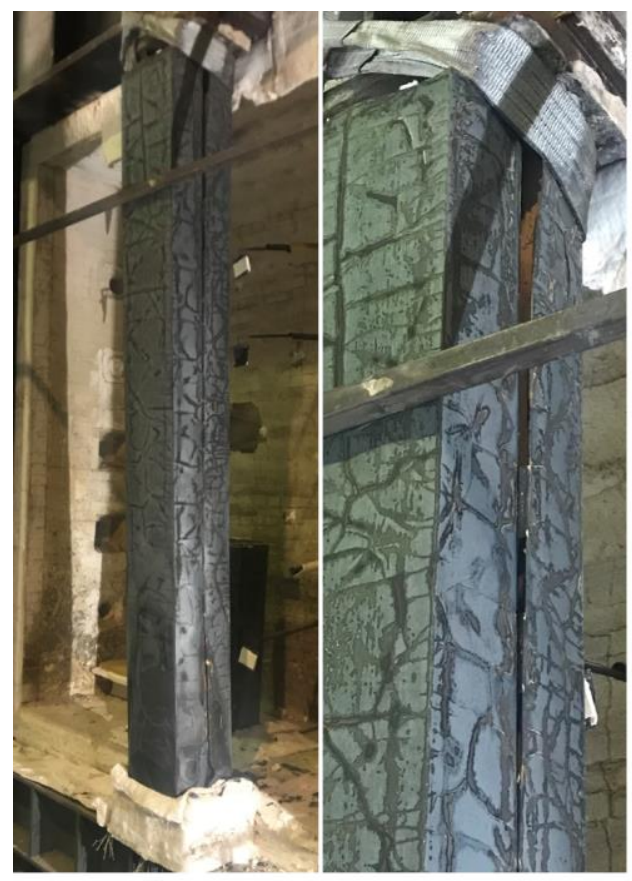

(a)

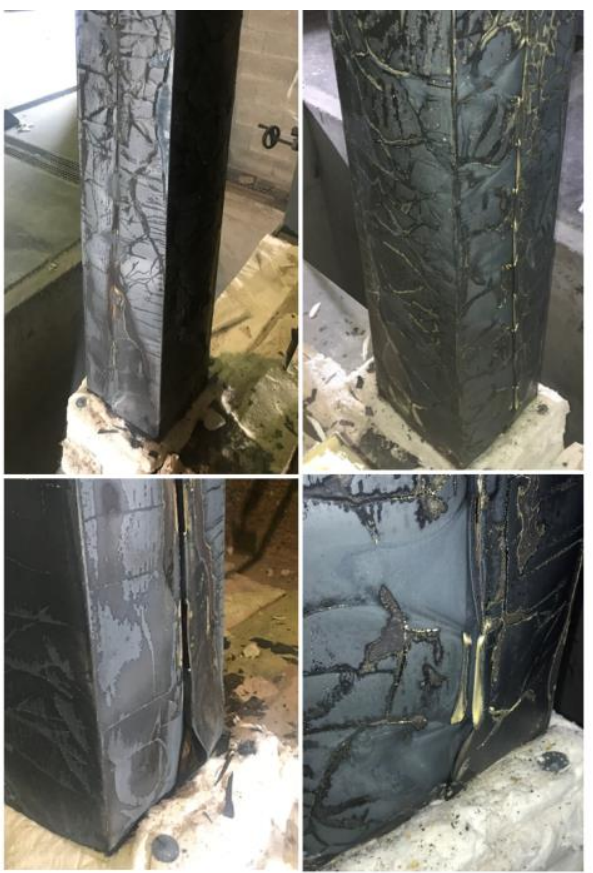

(b)

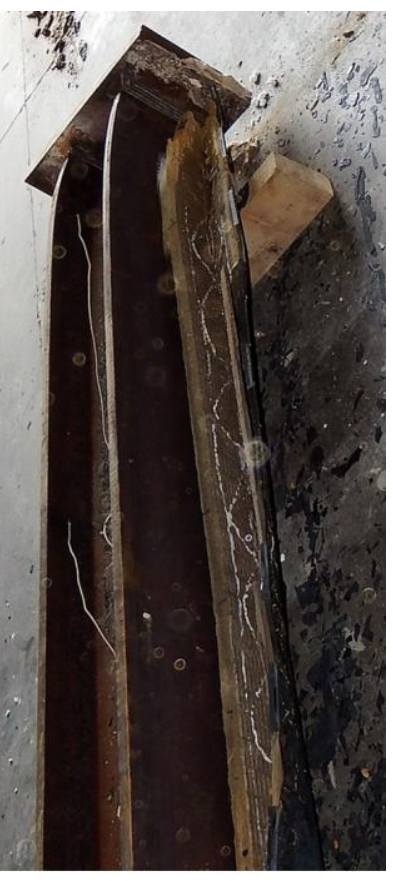

(c)

Figure 28 - Loaded specimen 12 after the 120 min of exposure to standard fire: a) Opening of two claws; b) Buckling of the steel sheets; c) Buckling of the HEM220 profile 


\section{Assessment of the fire protection}

\subsection{Temperature data}

This section aims to assess the fire protection thermal efficiency according to the norm EN13381-4 [25]. In this way, the protection can be certified. For that purpose, the first step was to collect the experimental data resulting from the large-scale tests. Table 10 summarises the times for the different specimens to reach design temperatures. Temperatures considered in this table are the overall mean temperatures calculated in Section 5.4. The norm evaluates the efficiency of the protection by considering individually every design temperature included in the scope of the assessment with step equal to $50{ }^{\circ} \mathrm{C}$ and starting from $350^{\circ} \mathrm{C}$.

Table 10 - Experimental times [min] to reach design temperatures

\begin{tabular}{ccccccccc}
\hline Specimen & Profile & $\begin{array}{c}\text { Box section } \\
\text { factor } \\
\end{array}$ & & \multicolumn{7}{c}{ Design temperatures $\theta_{\mathrm{a}}\left[{ }^{\circ} \mathrm{C}\right]$} \\
\hline 8 & HEB240 & $\left.\mathrm{A}_{\mathrm{p}} / \mathrm{m}^{-1}\right]$ & 350 & 400 & 450 & 500 & 550 & 600 \\
\hline 9 & HEB320 & 84 & 107.0 & 120.6 & 134.7 & 149.6 & 165.2 & 181.6 \\
10 & HEM220 & 64 & 117.4 & 132.6 & 148.3 & 164.5 & 181.5 & - \\
11 & HEM400 & 46 & 125.4 & 142.2 & 159.4 & 177.0 & - & - \\
12 & HEM220 & 64 & 101.5 & 113.9 & 126.6 & 139.7 & - & - \\
\hline
\end{tabular}

Based on the times collected here above, the stickability performance of the protection is evaluated by comparing the results of Specimens 10 and 12. Correction factors $k$ are calculated for each design temperature with the expressions defined in Eq. (11) and Eq. (12).

$\begin{array}{lll}\mathrm{k}=\mathrm{t}_{\mathrm{l}} / \mathrm{t}_{\mathrm{c}} & {[-]}\end{array}$

In these equations, $\mathrm{k}$ is the correction factor. $\mathrm{t}_{1}$ and $\mathrm{t}_{1}$ are the times to reach a design temperature for the loaded and unloaded specimens, respectively. $t_{c}$ is the corrected time for the unloaded specimen to reach the design temperature. $S$ and $S_{1}$ are box section factors of the loaded and unloaded profiles. $D$ and $D_{1}$ are protection thicknesses of the loaded and unloaded specimens. In the case of the present work, the protections of Specimens 10 and 12 are perfectly identical so that S equals S1 and D equals D1. The corrected time is therefore taken as the time for the unloaded specimen to reach the design temperature. Resulting correction factors $\mathrm{k}$ are calculated in Table 11. It has to be noted that correction factors for design temperatures of $550^{\circ} \mathrm{C}$ and $600{ }^{\circ} \mathrm{C}$ are found by linear extrapolation based on correction factors calculated for $450{ }^{\circ} \mathrm{C}$ and $500{ }^{\circ} \mathrm{C}$. Times for unloaded specimens to reach design temperatures are corrected against the loaded section and multiplied by the corresponding correction factor. Finally, the corrected time to be considered in the assessment procedure are summarized in Table 12.

Table 11 - Correction factors $\mathrm{k}$

\begin{tabular}{cccccc}
\hline \multicolumn{6}{c}{ Design temperatures $\theta_{\mathrm{a}}\left[{ }^{\circ} \mathrm{C}\right]$} \\
350 & 400 & 450 & 500 & 550 & 600 \\
\hline 0.810 & 0.801 & 0.794 & 0.789 & 0.784 & 0.779 \\
\hline
\end{tabular}


Table 12 - Corrected times [min] to reach design temperatures

\begin{tabular}{ccccccccc}
\hline Specimen & Profile & $\begin{array}{c}\text { Box section } \\
\text { factor } \\
\end{array}$ & & \multicolumn{7}{c}{ Design temperatures $\theta_{\mathrm{a}}\left[{ }^{\circ} \mathrm{C}\right]$} \\
\hline $\mathrm{A}_{\mathrm{p}} / \mathrm{V}\left[\mathrm{m}^{-1}\right]$ & 350 & 400 & 450 & 500 & 550 & 600 \\
\hline 8 & HEB240 & 94 & 86.6 & 96.5 & 107.0 & 118.0 & 129.5 & 141.5 \\
9 & HEB320 & 80 & 95.1 & 106.2 & 117.7 & 129.8 & 142.3 & - \\
10 & HEM220 & 64 & 101.5 & 113.9 & 126.6 & 139.7 & - & - \\
11 & HEM400 & 46 & 134.5 & 150.7 & - & - & - & - \\
\hline
\end{tabular}

\subsection{Assessment procedure}

To assess the performance of the fire protection system, Annex E of the norm 13381-4 prescribes four methods leading to similar results. However, it is up to the protection developers to select the most appropriate method yielding the best relation between experimental data and protection performance. Based on the corrected times summarized in Table 12, all four methods were employed. In particular, the one described in Annex E.4 of the norm and referred to as the numerical regression analysis appeared to provide the best results. Therefore, only this method is developed here. The numerical regression analysis used the formula defined in Eq. (13) to predict the time $t$ for a protected specimen to reach a design temperature $\theta_{a}$, as a function of protection thickness $d_{p}$, box section factor $A_{p} / V$ and design temperature $\theta_{\mathrm{a}}$. Parameters $a_{i}$ are coefficients to be determined by solving the regression equation using all the corrected time summarized in Table 12. Since the fire protection thickness $d_{p}$ is unique and equal to 45 $\mathrm{mm}$ in the framework of this certifying large-scale test, Eq. (13) can be simplified with Eq. (14) and written with a matrixial form in Eq. (15). Based on the 17 data summarized in Table 12, Eq. (15) can be developed.

$$
\begin{aligned}
& t=a_{0}+a_{1} \cdot d_{p}+a_{2} \cdot \frac{d_{p}}{A_{p} / V}+a_{3} \cdot \theta_{a}+a_{4} \cdot d_{p} \cdot \theta_{a}+a_{5} \cdot d_{p} \cdot \frac{\theta_{a}}{A_{p} / V}+a_{6} \cdot \frac{\theta_{a}}{A_{p} / V}+a_{7} \cdot \frac{1}{A_{p} / V} \\
& t=b_{0}+b 1 \cdot \frac{1}{A_{p} / V}+b_{2} \cdot \theta_{a}+b_{3} \cdot \frac{\theta_{a}}{A_{p} / V}
\end{aligned}
$$

$\underline{\underline{A}} \cdot \underline{b}=\underline{t}$

$$
\left[\begin{array}{cccc}
1 & 1 / 94 & 350 & 350 / 94 \\
1 & 1 / 94 & 400 & 400 / 94 \\
1 & 1 / 94 & 450 & 450 / 94 \\
1 & 1 / 94 & 500 & 500 / 94 \\
1 & 1 / 94 & 550 & 550 / 94 \\
1 & 1 / 94 & 600 & 600 / 94 \\
1 & 1 / 80 & 350 & 350 / 80 \\
1 & 1 / 80 & 400 & 400 / 80 \\
1 & 1 / 80 & 450 & 450 / 80 \\
1 & 1 / 80 & 500 & 500 / 80 \\
1 & 1 / 80 & 550 & 550 / 80 \\
1 & 1 / 64 & 350 & 350 / 64 \\
1 & 1 / 64 & 400 & 400 / 64 \\
1 & 1 / 64 & 450 & 450 / 64 \\
1 & 1 / 64 & 500 & 500 / 64 \\
1 & 1 / 46 & 350 & 350 / 46 \\
1 & 1 / 46 & 400 & 400 / 46
\end{array}\right] .\left[\begin{array}{c}
86.6 \\
\mathrm{~b}_{0} \\
\mathrm{~b}_{1} \\
\mathrm{~b}_{2} \\
\mathrm{~b}_{3}
\end{array}\right]=\left[\begin{array}{c}
96.5 \\
107.0 \\
118.0 \\
129.5 \\
141.5 \\
95.1 \\
106.2 \\
117.7 \\
129.8 \\
142.3 \\
101.5 \\
113.9 \\
126.6 \\
139.7 \\
134.5 \\
150.7
\end{array}\right]
$$


This matrix system is solved with the least squares method according to Eq. (16) and provides the values of coefficients $b_{i}$ to be used with Eq. (14). Times to reach design temperatures can be predicted for every specimen and they are summarized in Table 13.

$$
\begin{aligned}
& \underline{\mathrm{b}}=\left(\underline{\underline{\underline{A}}}^{\top} \underline{\underline{A}}\right)^{-1} \underline{\underline{A}}^{\top} \underline{\mathrm{t}} \\
& \underline{\mathrm{b}}=\left[\begin{array}{c}
-42.30 \\
4328 \\
0.230 \\
0.460
\end{array}\right]
\end{aligned}
$$

Table 13 - Predicted times [min] to reach design temperatures

\begin{tabular}{ccccccccc}
\hline Specimen & \multicolumn{3}{c}{$\begin{array}{c}\text { Box section } \\
\text { factor } \\
\end{array}$} & Profile & \multicolumn{5}{c}{ Design temperatures $\theta_{\mathrm{a}}\left[{ }^{\circ} \mathrm{C}\right]$} \\
& $\mathrm{A}_{\mathrm{p}} / \mathrm{V}\left[\mathrm{m}^{-1}\right]$ & 350 & 400 & 450 & 500 & 550 & 600 \\
\hline 8 & HEB240 & 94 & 84.6 & 96.1 & 107.7 & 119.2 & 130.8 & 142.3 \\
9 & HEB320 & 80 & 93.0 & 104.5 & 116.1 & 127.7 & 139.3 & - \\
10 & HEM220 & 64 & 107.4 & 119.1 & 130.8 & 142.4 & - & - \\
11 & HEM400 & 46 & 133.8 & 145.6 & - & - & - & - \\
\hline
\end{tabular}

These predicted times must fulfil the acceptability criteria required by the norm to ensure safe applications of the protection. These criteria are listed in

Table 14. With the values of the coefficients $b_{i}$ calculated based on corrected times with Eq. (16), it appeared that predicted times do not meet criteria 2 and 3. Provided that criteria 1,2 and 3 are not met, the norm recommends the reduction of the regression coefficients $b_{i}$ by multiplying them with a linear modification factor $x$. In the present case, the optimal modification factor was determined, as being equal to 0.97 , and was applied to coefficients $b_{i}$, as defined in Eq. (17). The modified coefficients $b_{i}^{\prime}$ were subsequently used with Eq. (14) to recalculate the predicted times to reach design temperatures, which are summarized in Table 15.

Table 14 - Acceptability criteria issued by the norm EN13381-4

1 For each specimen, the predicted time shall not exceed the corrected time by more than $15 \%$

2 The mean value of all percentage differences as calculated in 1 shall be less than zero

3 A maximum of $30 \%$ of individual values of all percentage differences as calculated in 1 shall be more than zero

4 As the section factor increases the fire resistance time decreases, provided all other parameters remain constant

5 As the the fire resistance time increases the temperatures increases, provided all other parameters remain constant

6 As the section factor increases the temperatures increases, provided all other parameters remain constant

$$
\begin{aligned}
& \underline{\mathrm{b}}^{\prime}=\mathrm{x} \cdot \underline{\mathrm{b}} \\
& \underline{\mathrm{b}^{\prime}}=\left[\begin{array}{c}
-40.98 \\
4195 \\
0.220 \\
0.440
\end{array}\right]
\end{aligned}
$$


Table 15 - Final predicted times to reach design temperatures

\begin{tabular}{|c|c|c|c|c|c|c|c|c|}
\hline \multirow{2}{*}{ Specimen } & \multirow{2}{*}{ Profile } & \multirow{2}{*}{$\begin{array}{l}\text { Box section } \\
\text { factor } \\
\mathrm{A}_{\mathrm{p}} / \mathrm{V}\left[\mathrm{m}^{-1}\right]\end{array}$} & \multicolumn{6}{|c|}{ Design temperatures $\theta_{\mathrm{a}}\left[{ }^{\circ} \mathrm{C}\right]$} \\
\hline & & & 350 & 400 & 450 & 500 & 550 & 600 \\
\hline 8 & HEB240 & 94 & 82.0 & 93.2 & 104.4 & 115.6 & 126.8 & 138.0 \\
\hline 9 & HEB320 & 80 & 90.1 & 101.3 & 112.6 & 123.8 & 135.0 & - \\
\hline 10 & HEM 220 & 64 & 104.2 & 115.5 & 126.8 & 138.1 & - & - \\
\hline 11 & HEM400 & 46 & 129.7 & 141.2 & - & - & - & - \\
\hline
\end{tabular}

With the modified regression coefficients $b_{i}{ }^{\prime}, E q . ~(14)$ can be transformed in Eq. (18) to yield the maximum box section factor that a protected profile can present, depending on the design temperature and the requested fire resistance period. Box section factors are summarized in Table 16 for different design temperatures and for different fire resistance periods. This table presents the results of this assessment procedure, in a straightforward way for applications.

$$
\frac{\mathrm{A}_{\mathrm{p}}}{\mathrm{V}}=\frac{\mathrm{b}_{1}{ }^{\prime}+\mathrm{b}_{3}{ }^{\prime} \theta_{\mathrm{a}}}{\mathrm{t}-\mathrm{b}_{0}{ }^{\prime}-\mathrm{b}_{2}{ }^{\prime} \theta_{\mathrm{a}}} \quad\left[\mathrm{m}^{-1}\right]
$$

Table 16 - Maximum box section factors Ap/ $\left[\mathrm{m}^{-1}\right]$

\begin{tabular}{ccccccc}
\hline Time & \multicolumn{6}{c}{ Design temperatures $\theta_{\mathrm{a}}\left[{ }^{\circ} \mathrm{C}\right]$} \\
{$[\mathrm{min}]$} & 350 & 400 & 450 & 500 & 550 & 600 \\
\hline 60 & $177.8^{*}$ & $323.2^{*}$ & - & - & - & - \\
90 & 79.9 & $100.5^{*}$ & $134.8^{*}$ & $203.9^{*}$ & - & - \\
120 & 51.5 & 59.5 & 70.2 & 85.5 & $108.9^{*}$ & $149.7^{*}$ \\
\hline \multicolumn{7}{c}{}
\end{tabular}

\subsection{Discussion of the results}

Results from the large-scale experimental tests and the assessment procedure, both performed according to the norm 13381-4, led to define the applicability range of the fire protection system. The fire protection, defined in Sections 2 and 5.2 with a rock wool thickness of $45 \mathrm{~mm}$ and $0.7 \mathrm{~mm}$ thick steel sheets, can be used to protect steel members presenting box section factors going from $46 \mathrm{~m}^{-1}$ to $94 \mathrm{~m}^{-1}$. Since Specimen 12 carried $100 \%$ of the required load, for a longer period than the test duration of $120 \mathrm{~min}$ in the thermomechanical test, assessment results are consequently applicable for any fire resistance period, equal or inferior to $120 \mathrm{~min}$. Furthermore, according to the norm 13381-4, the range of steel profiles addressed by the protection can be enlarged by $10 \%$ in term of box section factors, leading to a range going from 42 $\mathrm{m}^{-1}$ to $103 \mathrm{~m}^{-1}$. Even though the fire protection system was assessed for steel members presenting ' $\mathrm{l}$ ' and ' $\mathrm{H}$ ' cross-sections, the system developed can also be applied with structural hollow cross-sections with the same range of box section factors. 


\section{Cost analysis}

As mentioned in the introduction, costs relative to a fire protection system must be divided in two parts, direct- and indirect costs. This last section establishes an accurate estimation of the plug-and-play system direct cost and compare it with others fire protection systems, i.e. intumescent paints, sprays and boards. Direct costs were straightforward to evaluate by considering actual prices of the specimens manufactured for experimental campaigns and the time spent for their production and installation. Indirect costs were far less straightforward to estimate due to the lack of data. For this reason, indirect costs were not quantified but only discussed. Direct cost is detailed in Table 17 as the sum of the material and labour costs. Data for the material cost estimation were taken from the suppliers [27][32][33]. Data for the labour cost estimation were based on observations and the European average hourly labour cost [34]. Direct cost is expressed as a unit cost $\left[€ / \mathrm{m}^{2}\right]$ to be compared with other systems. Unit costs data for different fire protection systems are provided by the Bauforumstahl [35], i.e. a steel construction forum established in Dusseldorf, Germany. For each system, Table 18 defines unit cost ranges found for fire resistances of 30 $\mathrm{min}, 60 \mathrm{~min}, 90 \mathrm{~min}$ and $120 \mathrm{~min}$. Unit cost for intumescent paints depends on the application method. It tends to be more expensive when applied on site than when pre-applied in workshop. Unit costs for sprays and boards varies with the composition and the quality of the product. It must be noted that unit cost ranges for R120 fire resistance were estimated by linear extrapolation based on the available data. That is a fair assumption since the fire resistance of a system in the same way as its cost, is directly proportional to its protection thickness. The fire protection system developed in the framework of this research is referred as the plug-and-play system.

Table 17 - Direct cost details of the plug-and-play system

\begin{tabular}{lcc}
\hline Item & Value & Unit \\
\hline $15 \mathrm{~mm}$ thick rock wool board & 10 & {$\left[€ / \mathrm{m}^{2}\right]$} \\
$30 \mathrm{~mm}$ thick rock wool board & 22 & {$\left[€ / \mathrm{m}^{2}\right]$} \\
Glue & 2 & {$\left[€ / \mathrm{m}^{2}\right]$} \\
Steel sheet & 16 & {$\left[€ / \mathrm{m}^{2}\right]$} \\
\hline Material cost & $\mathbf{5 0}$ & {$\left[€ / \mathrm{m}^{2}\right]$} \\
Installation time for 2 workers & 0.25 & {$\left[\mathrm{~h} / \mathrm{m}^{2}\right]$} \\
Manufacturing time for 1 worker & 0.5 & {$\left[\mathrm{~h} / \mathrm{m}^{2}\right]$} \\
Average hourly labour costs & 27 & {$[€ / \mathrm{h}]$} \\
\hline Worker Cost & $\mathbf{2 7}$ & {$\left[€ / \mathrm{m}^{2}\right]$} \\
\hline Direct cost & $\mathbf{7 7}$ & {$\left[€ / \mathrm{m}^{\mathbf{2}}\right]$} \\
\hline
\end{tabular}

Table 18 - Unit cost for different fire protection systems

\begin{tabular}{lcccc}
\hline \multirow{2}{*}{ Fire protection systems } & \multicolumn{4}{c}{ Unit cost $\left[\boldsymbol{\epsilon} / \mathbf{m}^{\mathbf{2}}\right]$} \\
& $\mathrm{R} 30$ & $\mathrm{R} 60$ & $\mathrm{R} 90$ & $\mathrm{R} 120$ \\
\hline Intumescent paints & $15-28$ & $38-60$ & $65-100$ & $92-140^{*}$ \\
Sprays & $18-28$ & $20-35$ & $25-40$ & $30-45^{*}$ \\
Boards & $20-40$ & $30-55$ & $40-65$ & $50-75^{*}$ \\
Plug-and-play & - & - & - & 77 \\
\hline
\end{tabular}

*Unit cost estimated by linear extrapolation 
The consideration of unit cost is an indicative basis for the comparison of fire protection systems. Nevertheless, it must be noted that the surfaces or the areas to be protected by the different system is not always identical. Figure 29 illustrates box- and actual areas for I an $\mathrm{H}$ steel sections exposed to fire. Box area Ap must be considered when protected with boards and plug-and-play systems, while actual area Am must be considered when protected with intumescent paints or sprays. Box- and actual areas are identical for hollow square steel sections.

A comparison of the four fire protection systems when applied on a $3 \mathrm{~m}$ high HEB300 steel profile is detailed in Table 19. Box- and actual areas for a $3 \mathrm{~m}$ high HEB300 steel profile were found to be equal to $3.60 \mathrm{~m}^{2}$ and $5.19 \mathrm{~m}^{2}$, respectively. Therefore, by multiplying the unit cost of each system with the appropriate area exposed to fire, actual cost ranges could be defined and permitted an unbiased cost comparison between the different systems. It can be observed that the plug-and-play system appear to be competitive compared with intumescent paints, while sprays and boards systems remain less expensive solution. However, it must be recalled that aesthetic aspects are not the same for the four protections systems and that comparison is based on direct costs only.

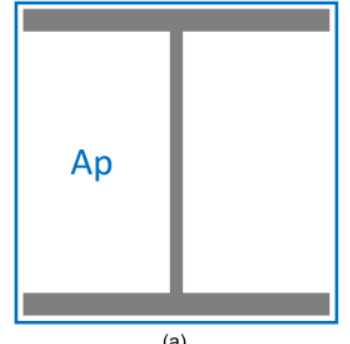

(a)

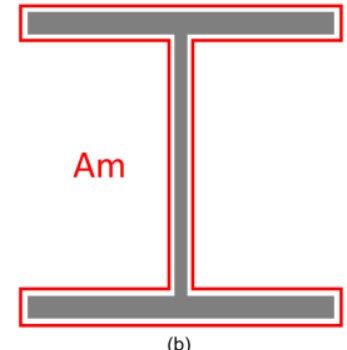

(b)

Figure 29 - Area exposed to fire: a) Box area $A_{p}$; b) Actual area $A_{m}$

Table 19 - Cost comparison of fire protection systems applied on a 3m high HEB300 steel profile

\begin{tabular}{lccc}
\hline Fire protection systems & Unit cost $\left[\boldsymbol{\epsilon} / \mathbf{m}^{\mathbf{2}}\right]$ & Area $\left[\mathbf{m}^{\mathbf{2}}\right]$ & Actual cost [€] \\
\hline Intumescent paints & $92-140$ & 5.19 & $477-726$ \\
Sprays & $30-45$ & 5.19 & $156-233$ \\
Boards & $50-75$ & 3.60 & $180-270$ \\
Plug-and-play & 77 & 3.60 & 277 \\
\hline
\end{tabular}

Indirect costs of a fire protection refer to the costs generated within a construction project due to application of the protection on site. Since these costs are not related to the fire protection itself, they are often unconsidered when solutions are compared by fire design stakeholders. Indirect costs are usually quantified in terms of site delay and damage which have to be covered by the construction project. Fire protections requiring important installation time on site are more likely to generate delays and represent longer risk exposure for technicians. That is the case for boards, sprays and paints when applied on site. Particularly, sprays and intumescent paints can significantly impact the accessibility to a construction site area because they are wet applications and require a drying period. Eventually, by considering direct and indirect costs, the plug-and-play protection system developed in this work constitutes a cost-effective solution and it is in the community interest to take it into consideration when a fire protection has to be selected. 


\section{Conclusion}

This paper presented the development of an innovative and cost-efficient plug-and-play fire protection system for steel columns. The different key steps of the protection design were detailed. It started with the conception of the fire protection that consisted in the definition of the main components, i.e. rock wool and steel sheet, and the design of the plug-and-play connection system based on bent steel sheets forming connection claws. Small-scale experimental tests were performed in an early stage of the protection design to evaluate its thermo-mechanical behaviour and its thermal insulation efficiency. Small-scale tests provided conclusive results regarding the plug-and-play system since no opening of connection claws was observed out of the seven specimens. 3D numerical model was developed with the software ABAQUS and showed the same observations, i.e. no connection claws opening after 120 min of exposure to standard fire. 2D thermal models were developed with the finite element software SAFIR and calibrated against experimental results. Subsequently the analytical model prescribed in Eurocode 3 was adopted to verify the results of 2D thermal models. Both models were in line and predicted similar steel temperature evolution with time. Consequently, these models served for the proper definition of the large-scale experimental campaign performed in the fire laboratory at the University of Liège. Large-scale tests aimed to evaluate five specimens to certify a single version of the fire protection according to the norm EN 13381-4 and allowed therefore its application in Europe. Furthermore, large-scale experimental campaign namely allowed the thermo-mechanical evaluation of the protection system when equipped around a $3.1 \mathrm{~m}$ high steel column loaded to $60 \%$ of its vertical bearing capacity. Thermal results obtained with large scale tests were finally found to be better than the ones observed with small-scale experimental tests. That demonstrated the thermal efficiency of the developed fire protection. Additionally, a cost analysis of the plug-and-play protection system and a cost comparison with existing solutions were performed. That demonstrated the cost-efficiency of the developed protection as well as in term of direct as indirect costs. Eventually the plug-and-play fire protection system developed must be manufactured using steel sheets with a minimal thickness of $0.7 \mathrm{~mm}$ and with a rockwool thickness of $45 \mathrm{~mm}$ composed of two layers $(15 \mathrm{~mm}+30 \mathrm{~mm})$. This system is certified to protect steel profiles presenting ' $\mathrm{H}$ ', ' $\mathrm{l}$ ' and hollows sections with box section factors going from $42 \mathrm{~m}^{-1}$ to $103 \mathrm{~m}^{-1}$, by maintaining steel temperature below $550^{\circ} \mathrm{C}$ for $120 \mathrm{~min}$ of exposure to standard fire.

\section{Acknowledgments}

The development the fire protection system was entirely funded by the European commission through the XP-Resilience project and the grant agreement number 721816. The research relative to this plugand-play system was undertaken in the Global R\&D Center of ArcelorMittal in Esch-sur-Alzette (Luxembourg) which provided scientific and logistic support. ROCKWOOL ${ }^{\circledR}$ provided for free the rockwool board used in the specimens manufacturing. Small-scale experimental tests campaign was achieved in the metallurgy research centre CRM in Liège (Belgium). Large-scale experimental tests were achieved in the fire laboratory at the University of Liège (Belgium). Eventually, valuable scientific support was brought by the University of Trento (Italy). 


\section{References}

[1] M. K. Islam, M. J. Hasan, and T. Manzur, "Behavior of typical steel column sections under standard fire," in International Conference on Disaster Risk Management, 2019.

[2] International Organization for Standardization, "Fire resistance test - Elements of building construction - Part 1: General Requirements ISO/FDIS 834-1." Geneva, 1999.

[3] L. Petukhovskaia, "Passive fire protection methods of load-bearing structures in case of hydrocarbon fire," Saimaa University of Applied Sciences, 2018.

[4] H. Leborgne and L. Thomas, "Techniques de protections rapportées des structures en acier," Constr. Métallique, vol. 3, pp. 123-135, 1999.

[5] National Institute of Standards and Technology - NIST, "Fire protection of structural steel in highrise buildings." 2004.

[6] A. Lucherini and C. Maluk, "Intumescent coatings used for the fire-safe design of steel structures : A review," J. Constr. Steel Res., vol. 162, p. 105712, 2019.

[7] D. De Silva, A. Bilotta, and E. Nigro, "Experimental investigation on steel elements protected with intumescent coating," Constr. Build. Mater., vol. 205, pp. 232-244, 2019.

[8] G. J. Griffin, "The Modeling of heat transfer across intumescent polymer coatings," J. Fire Sci., vol. 28, pp. 249-277, 2010.

[9] B. Gardelle, S. Duquesne, P. Vandereecken, and S. Bourbigot, "Resistance to fire of silicone-based coatings : Fire protection of steel against cellulosic fire," J. Fire Sci., pp. 374-387, 2014.

[10] P. Luangtriratana, B. K. Kandola, S. Duquesne, and S. Bourbigot, "Quantification of thermal barrier efficiency of intumescent coatings on glass fibre-reinforced epoxy composites," Coatings, pp. 1-18, 2018.

[11] C. Chen, J. Zeng, and B. Shen, "Experimental investigation on performance of intumescent coating for steel plate at elevated temperature," Cent. South Univ. Press, vol. 22, pp. 3151-3158, 2015.

[12] T. Mariappan, "Recent developments of intumescent fire protection coatings for structural steel : A review," J. Fire Sci., vol. 34, no. 2, pp. 120-163, 2016.

[13] G. E. Fulmer, "Method of making a fire-retardant product having a foamed lore and a fireretardant protective layer," US 4349494, 1982.

[14] Q. Zhang and V. C. Li, "Development of durable spray-applied fire-resistive Engineered Cementitious Composites ( SFR-ECC)," Cem. Concr. Compos., vol. 60, pp. 10-16, 2015.

[15] X. Zhang, L. Peng, Z. Ni, T. Ni, Y. Huang, and Y. Zhou, "Experimental study on the fire performance of tubular steel columns with membrane protections for prefabricated and modular steel construction," Materials (Basel)., pp. 1-12, 2018.

[16] P. Keerthan and M. Mahendran, "Numerical studies of gypsum plasterboard panels under standard fire conditions," Fire Saf. J., vol. 53, pp. 105-119, 2012. 
[17] S. Gottfried, "Fire and heat protection wrap for structural steel columns, beams and open web joists," WO 01/72506 A1, 2001.

[18] D. ZAGO and R. Keiser, "Covering and fire protection device for metal girders," WO 2011/045247 A1, 2011.

[19] A. S. Parker, "Plasterboard to column clip," US 3748815, 1973.

[20] P. P. Ramos, "Fire protection system for wide flange steel columns and beams," US 2013/0167475 A1, 2013.

[21] O. Akaa, A. Abu, M. Spearpoint, and S. Giovinazzi, "Optimising design decision-making for steel structures in fire using a hybrid analysis technique," Fire Saf. J., vol. 91, no. February, pp. 532541, 2017.

[22] O. U. Akaa, A. Abu, M. Spearpoint, and S. Giovinazzi, "A group-AHP decision analysis for the selection of applied fire protection to steel structures," Fire Saf. J., vol. 86, no. March, pp. 95105, 2016.

[23] J. W. Lim, T. Baalisampang, V. Garaniya, R. Abbassi, F. Khan, and J. Ji, "Numerical analysis of performances of passive fire protections in processing facilities," J. Loss Prev. Process Ind., vol. 62, no. September, pp. 1-12, 2019.

[24] European Committee for Standardization CEN, "Eurocode 3: Design of steel structures - Part 1-2: General rules - structural fire design. EN 1993-1-2." European Commitee for Standardization, CEN, Brussels, 2005.

[25] European Committee for Standardization CEN, "Test methods for determining the contribution to the fire resistance of structural members - Part $4:$ Applied passive protection to steel members Contents." pp. 1-85, 2011.

[26] W. Wang and G. Li, "Fire-resistance study of restrained steel columns with partial damage to fire protection," Fire Saf. J., vol. 44, no. 8, pp. 1088-1094, 2009.

[27] ROCKWOOL, "Conlit Steelprotect Board - Technical specifications." [Online]. Available: https://fr.rockwool.be/produits/isolation-technique/applications-ignifuges/conlit-steelprotectboard/\#Tools\&Downloads. [Accessed: 26-Feb-2020].

[28] Dassault Systemes, "ABAQUS - Software for nonlinear finite element analysis," 2016. [Online]. Available: https://www.simuleon.com/simulia-abaqus/abaqus-standard/. [Accessed: 26-Feb2020].

[29] J. Franssen, "SAFIR: A Thermal/Structural Program for Modelling Structures Under Fire," Eng. J., no. Third Quarter, pp. 143-158, 2005.

[30] J.-B. Schleich, "Implementation of Eurocodes - Handbook 5 - Design of buildings for the fire situation," Leonardo da Vinci pilot project. Luxembourg, 2005.

[31] European Committee for Standardization CEN, "Eurocode 3: Design of steel structures - Part 1-1: General rules and rules for buildings. EN 1993-1-1." European Committee for Standardization CEN, Brussels, 2005.

[32] EMFI, "ISOLEMFI 3300- technical specifications," 2018. [Online]. Available:

http://www.emfi.com/en/produits/products.html?cp=50040A. [Accessed: 26-Feb-2020]. 
[33] ArcelorMittal, "ArcelorMittal Construction Products," 2017. [Online]. Available: www.arcelormittalconstruction.be. [Accessed: 27-Feb-2020].

[34] E. Charlton, "Where labour costs the most (and least) in the European Union," World Economic Forum, 2019. [Online]. Available: https://www.weforum.org/agenda/2019/05/chart-labourcosts-in-european-union. [Accessed: 27-Feb-2020].

[35] BauforumStahl, "Kosten im Stahlbau 2019 Basisinformationen zur Kalkulation / Steel construction costs 2019 - Basic information about calculation," CEEC - European Council of Construction Economists, 2019. [Online]. Available:

https://bauforumstahl.de/fileadmin/user_upload/bauforumstahl.de/wirtschaft-undpolitik/baukosten/Kosten_im_Stahlbau_2019v2.pdf. [Accessed: 26-Feb-2020]. 